\title{
Current Advances and Limitations in Modeling ALS/FTD in a Dish Using Induced Pluripotent Stem Cells
}

\author{
Wenting Guo ${ }^{1,2}$, Laura Fumagalli ${ }^{1,2}$, Robert Prior ${ }^{1,2}$ and Ludo Van Den Bosch ${ }^{1,2 *}$ \\ ${ }^{1}$ KU Leuven-Department of Neurosciences, Experimental Neurology and Leuven Institute for Neuroscience and Disease, \\ Leuven, Belgium, ${ }^{2}$ Laboratory of Neurobiology, VIB \& KU Leuven Center for Brain \& Disease Research, Leuven, Belgium
}

\section{OPEN ACCESS}

Edited by:

Dustin R. Wakeman,

RxGen (United States), United States

Reviewed by:

Smitha Karunakaran,

Indian Institute of Science, India

Renata Santos,

UMR8197 Institut de biologie de l'Ecole Normale Supérieure (IBENS),

France

*Correspondence:

Ludo Van Den Bosch ludo.vandenbosch@kuleuven.vib.be

Specialty section:

This article was submitted to

Neurodegeneration,

a section of the journal

Frontiers in Neuroscience

Received: 01 September 2017 Accepted: 20 November 2017 Published: 13 December 2017

Citation:

Guo W, Fumagalli L, Prior $R$ and

Van Den Bosch L (2017) Current Advances and Limitations in Modeling ALS/FTD in a Dish Using Induced

Pluripotent Stem Cells.

Front. Neurosci. 11:671. doi: 10.3389/fnins.2017.00671
Amyotrophic lateral sclerosis (ALS) and frontotemporal dementia (FTD) are two age-dependent multifactorial neurodegenerative disorders, which are typically characterized by the selective death of motor neurons and cerebral cortex neurons, respectively. These two diseases share many clinical, genetic and pathological aspects. During the past decade, cell reprogramming technologies enabled researchers to generate human induced pluripotent stem cells (iPSCs) from somatic cells. This resulted in the unique opportunity to obtain specific neuronal and non-neuronal cell types from patients which could be used for basic research. Moreover, these in vitro models can mimic not only the familial forms of ALS/FTD, but also sporadic cases without known genetic cause. At present, there have been extensive technical advances in the generation of iPSCs, as well as in the differentiation procedures to obtain iPSC-derived motor neurons, cortical neurons and non-neuronal cells. The major challenge at this moment is to determine whether these iPSC-derived cells show relevant phenotypes that recapitulate complex diseases. In this review, we will summarize the work related to IPSC models of ALS and FTD. In addition, we will discuss potential drawbacks and solutions for establishing more trustworthy iPSC models for both ALS and FTD.

Keywords: amyotrophic lateral sclerosis, frontotemporal dementia, iPSC, neurodegeneration, motor neuron

\section{INTRODUCTION}

\section{Amyotrophic Lateral Sclerosis}

Amyotrophic lateral sclerosis (ALS) is a progressive neurodegenerative disease caused by the selective death of both upper and lower motor neurons (Renton et al., 2014). The disease is also known as Lou Gehrig's disease, as it was named after the American baseball player who was diagnosed with ALS in 1939 and died as a result of the disease (Taylor et al., 2016). Typically, the onset of this disease is in late midlife and it is mostly fatal within 3-5 years after the detection of the first symptoms (Renton et al., 2014; Taylor et al., 2016). Currently, there are no effective treatments for ALS. The first FDA-approved drug for the treatment of ALS was riluzole, which is thought to interfere with glutamate metabolism. However, riluzole only increases survival by a few months (Petrov et al., 2017). Recently, edaravone was approved by FDA after it was shown that intravenous injection of this anti-oxidant slows down the disease progression in a subpopulation of ALS patients (Hardiman and van den Berg, 2017).

The incidence of ALS varies between 0.3 and 3.6 new cases per 100,000 per year depending on the demographics (Henry et al., 2015). In 90\% of ALS cases, there is no familial history and these patients are considered as sporadic ALS patients. In $\sim 10 \%$ of patients, the disease is inherited 
and these are classified as familial ALS (Renton et al., 2014; Henry et al., 2015). The genetic etiology of sporadic ALS and of $\sim 30 \%$ of familial ALS (European descent) is still unknown (He et al., 2015). The major genetic pattern of inheritance of familial ALS is autosomal dominant, but other hereditary patterns have been reported. The most prevalent mutated genes are superoxide dismutase 1 (SOD1), chromosome 9 open reading frame 72 (C9ORF72), TAR DNA-binding protein 43 (TARDBP) and fused in sarcoma (FUS) (Renton et al., 2014).

\section{Frontotemporal Dementia}

Frontotemporal dementia (FTD) is comprised of a group of disorders caused by progressive neurodegeneration in the frontal and/or temporal lobes of the brain (Bang et al., 2015). It is also called Pick's disease after the physician Arnold Pick, who first described the disease in 1892 (Boxer and Miller, 2005). FTD accounts for up to $10-15 \%$ of all dementia cases and is considered the second most common form of early-onset dementia in people younger than 65 years of age, after Alzheimer's disease (Karageorgiou and Miller, 2014; Lashley et al., 2015). Patients show changes in social and personality behavior, apathy, blunting of emotions, and/or deficits in both expressive and receptive language (Bang et al., 2015; Burrell et al., 2016). Unfortunately, there is no effective treatment for FTD yet. The exact cause of FTD is still unknown, although in $40-50 \%$ of FTD cases there is a family history (Fong et al., 2012; Ng et al., 2015). Several gene mutations were linked to FTD. The most frequently mutated genes include Microtubule Associated Protein Tau (MAPT), Progranulin (GRN), and C9ORF72 (Bang et al., 2015; Burrell et al., 2016).

\section{ALS and FTD, the Extremities of a Disease Spectrum}

Although ALS and FTD mostly occur as separate diseases, there are more and more common aspects identified for both disorders. Clinically, a number of patients diagnosed with ALS show signs of FTD such as behavioral, cognitive, or language dysfunctions (Ling et al., 2013; Ng et al., 2015). The frequency of FTD clinical features in ALS varies amongst different reports, but it was claimed that some FTD-related symptoms can be detected in up to $50 \%$ of ALS patients (Ferrari et al., 2011). Additionally, the opposite also occurs, in that some FTD patients develop motor symptoms during the disease process. Moreover, ALS and FTD can occur within the same family (Ferrari et al., 2011; Ling et al., 2013; Ng et al., 2015). In terms of genetics, hexanucleotide repeat expansions in C9ORF72, as well as mutations in the Valosin-Containing Protein (VCP) gene are found in both ALS and FTD (Ling et al., 2013). Furthermore, the repeat expansions in C9ORF72 cause the disease in a high proportion of families in which both FTD and ALS occurs (Cooper-Knock et al., 2015). Interestingly, FTD and ALS also share some pathological hallmarks; the most important being the presence of neuronal inclusions of TDP-43, the gene product of the TARDBP gene (Ling et al., 2013). Similarly, FUS inclusions are observed in a limited number of ALS, as well as FTD patients (Ling et al., 2013). In addition, nuclear repeat-containing RNA foci as well as inclusions containing dipeptide repeat proteins (DPRs), both specific pathological characteristics of patients with C9ORF72 expansions, are detected in post mortem material of these ALS and FTD patients (Ling et al., 2013; Cooper-Knock et al., 2015).

\section{Multiple Pathological Mechanisms Have Been Associated with ALS/FTD}

A large number of biological processes have already been suggested to be involved in ALS and some of these could also play a role in FTD. Amongst others, these include excitotoxicity, hyperexcitability, astrocytosis, neuroinflammation, mitochondrial dysfunction, axonal abnormalities, dysregulated autophagy, abnormal RNA metabolism, problems with stress granule dynamics, and nucleocytoplasmic transport defects.

The pathogenic mechanism for which there is ample evidence that it indeed plays a role in ALS patients is excitotoxicity (Van Den Bosch et al., 2006). Excitotoxicity is the process of neuronal degeneration caused by overstimulation of glutamate receptors. One of the major arguments for an involvement of excitotoxicity in the ALS disease process is that riluzole has anti-excitotoxic properties (Miller et al., 2003).

More recently, at least part of the therapeutic effect of riluzole was linked to a (transient) effect on axonal and cortical hyperexcitability (Vucic et al., 2013). Peripheral and central hyperexcitability mirrors clinical features (fasciculations) and neurophysiological findings (increased intracortical excitability). Although there are no treatments approved by the FDA for FTD until now, one transgenic mouse model carrying human TDP-43 ${ }^{\mathrm{A} 315 \mathrm{~T}}$ showed hyperactive somatostatin interneurons that disinhibited pyramidal neurons, which contributed to excitotoxicity (Zhang W. et al., 2016). In addition, another transgenic mouse model with a human $\mathrm{Tau}^{\mathrm{A} 152 \mathrm{~T}}$ mutation showed excitotoxicity mediated by NR2B-containing NMDA receptors due to enhanced extracellular glutamate (Decker et al., 2016).

It is well-known that astrocytes as well as microglia are activated during the disease process. The activated astrocytes release toxic factors, of which the identity is largely unknown. Furthermore, they seem to be soluble in nature, as mutant astrocyte-conditioned medium is also toxic for primary motor neurons of embryonic stem cell (ESCs) derived motor neurons (Nagai et al., 2007). In addition, mutant SOD1 expressing astrocytes fail to protect neurons from excitotoxicity. Astrocytes can increase the excitability and $\mathrm{Ca}^{2+}$ influx in motor neurons by increasing the $\mathrm{Na}^{+}$current or by decreasing the neuronal GluR2 expression leading to a higher $\mathrm{Ca}^{2+}$ permeability of the AMPA receptor, ultimately leading to neuronal excitotoxicity (Van Damme et al., 2007; Fritz et al., 2013). When microglia are activated during the disease process, the cell body enlarges and the processes get thicker. Microglia mimic properties of antigenpresenting cells and start to interact with T-cells, which infiltrate in the spinal cord and cortex (Engelhardt et al., 1993; Alexianu et al., 2001). This microglial activation starts before disease onset and the number of activated microglia and infiltrated T-cells increases with disease progression (Hall et al., 1998; Alexianu et al., 2001). Similarly, when GRN was injected in mouse brain, 
an increase of Ibal-positive microglia around the injection site was observed. This indicates that there could be a link between FTD and microglial phagocytosis (Pickford et al., 2011).

Both in animal models and in ALS/FTD patients, dysfunctional mitochondria are observed. Mitochondria are not only crucial for ATP synthesis, but are also involved in intracellular $\mathrm{Ca}^{2+}$ homeostasis and induction of apoptosis. As a consequence, abnormal functioning of mitochondria can cause cell death. In the mutant SOD1 mouse model, swollen and vacuolated mitochondria were observed in motor neurons before the first signs of motor neuron degeneration appear (Wong et al., 1995; Kong and Xu, 1998; Higgins et al., 2003). From analysis of the mitochondrial functionality, a decrease of mitochondrial membrane potential was observed in fibroblasts from ALS/FTD patients carrying mutant TARDBP (Onesto et al., 2016). Interestingly, increased oxygen consumption and mitochondrial hyperpolarization were observed in fibroblasts from ALS/FTD patients carrying mutant C9ORF72 (Onesto et al., 2016). Similar abnormalities are found in sporadic ALS/FTD patients (Sasaki and Iwata, 2007). In general, dysfunctions in mitochondrial respiration and ATP synthesis, axonal transport of mitochondria, mitochondrial dynamics, $\mathrm{Ca}^{2+}$ buffering (which could lead to excitotoxicity) and induction of apoptosis are all seen in SOD1 mouse models (Kawamata and Manfredi, 2010). Moreover, these abnormalities are not restricted to the mutant SOD1 pathogenesis, also mice overexpressing human TDP-43 have abnormal distribution of mitochondria and changes in mitochondrial dynamics (Xu et al., 2010; Wang et al., 2013), while neuronal cultures expressing ALS-linked FUS mutants contain smaller mitochondria (Tradewell et al., 2012).

Neurons in general and motor neurons in particular are highly dependent on axonal transport mechanisms along their very long axons to bring proteins, organelles and other cargoes to their required sites. Microtubules form tracks along axons on which different cargoes are transported with the help of motor proteins. Since axonal swellings containing neurofilaments were observed in sporadic and familial ALS patients (Okamoto et al., 1990; Sasaki and Maruyama, 1992), axonal transport defects have been intensively studied in ALS (De Vos and Hafezparast, 2017).

ALS is also characterized by the accumulation of ubiquitinated proteins. In the majority of ALS cases, these accumulations contain ubiquitinated TDP-43 even when there are no mutations in the TARDBP gene (Neumann et al., 2006). Both autophagy and the ubiquitin-proteasome system (UPS) systems are responsible for the proteostasis in eukaryotes and the prevention of protein aggregation. After deletion of two different essential genes for autophagy (Atg5 or Atg7), each of these transgenic mice develop a neurodegenerative phenotype which suggests an essential role of autophagy in neurons (Hara et al., 2006; Komatsu et al., 2006). Ubiquitin-positive immunoreactive inclusions have been reported as the neuropathological hallmark of FTD patients (Brun et al., 1994).

Disturbances in the RNA metabolism were linked to ALS/FTD after the discovery of mutations in TARDBP and FUS, encoding two different RNA-binding proteins (TDP-43 and FUS) (Ling et al., 2013). Under normal conditions, both TDP-43 and FUS are localized in the nucleus. In brain and spinal cord of ALS patients, TDP-43 and FUS are in the cytoplasm of the neurons and sometimes also of the glial cells. In response to stress, both TDP-43 and FUS localize to the stress granules present in the cytoplasm. In these stress granules, mRNA is translationally inactive. Both TDP-43 and FUS contain low-complexity domains which are essential for their localization in these stress granules. After periods of stress, the stress granules resolve and mRNA becomes available again to be translated. FUS mutations seem to accelerate the transition from the liquid to the aggregated state in these stress granules (Patel et al., 2015). Interestingly, FUS inclusions have also been reported in FTD patients which do not carry FUS mutations (Lagier-Tourenne et al., 2010). A number of recent papers link the toxicity of the hexanucleotide repeats in C9ORF72 to an interference with the nucleocytoplasmic transport process (Boeynaems et al., 2016). This could also explain the cytoplasmic mislocalization of TDP-43 in patients with hexanucleotide repeats in C9ORF72.

Despite our understanding of the genetic causes and of the pathological processes responsible for ALS/FTD, many potential therapies were unsuccessful in human clinical trials. However, most of these therapeutic strategies were based on preclinical research on animal models. Successful modeling of ALS and FTD by using human materials could deepen our knowledge of these complex diseases, aid in the identification of therapeutic targets and overall, have a significant impact on ALS/FTD research (Picher-Martel et al., 2016; Sances et al., 2016; Lee and Huang, 2017).

\section{iPSC-DERIVED MODELS FOR ALS/FTD}

Until now, rodent models are the most widely used ALS/FTD models both to study disease mechanisms and to test potential treatments with newly developed compounds (Petrov et al., 2017). With the advancement of genetic and technological approaches, a wide range of additional model systems became available to study these diseases. These model systems differ from in vitro to in vivo, from invertebrates to vertebrates, from yeast to human iPSCs. It is clear that all these model system have their advantages and disadvantages (Van Damme et al., 2017).

In recent years, several publications identified a number of pathogenic molecular mechanisms of ALS/FTD using human iPSC models (Table 1). Most of these studies focused on familial types of these diseases because the known mutations could give a clue to the underlying mechanism. We will summarize the results obtained with these iPSC models based on the different mutated genes. In addition, we will discuss the results obtained starting from iPSCs from sporadic ALS/FTD patients (Figure 1).

\section{Advantages of iPSCs as a Model System}

iPSCs are pluripotent stem cells that are generated directly from adult cells. The iPSC technology was developed by Shinya Yamanaka's lab by introducing four specific transcription factors into adult cells and converting these cells into pluripotent stem cells (Takahashi et al., 2007). As one of the newest ALS model systems, this technology allows for the generation of iPSCs from patient-derived somatic cells from ALS patients and opens new 
TABLE 1 | Summary of published iPSC models of ALS and FTD.

\begin{tabular}{|c|c|c|c|c|c|}
\hline Disease & Gene mutation & $\begin{array}{l}\text { Reprogramming } \\
\text { strategy }\end{array}$ & $\begin{array}{l}\text { iPSC-derived cell } \\
\text { subtype }\end{array}$ & ALS/FTD phenotype & References \\
\hline ALS & $\begin{array}{l}\text { SOD1A4V } \\
\text { SOD1D90A }\end{array}$ & $\begin{array}{l}\text { Retroviral/Sendai } \\
\text { viral }\end{array}$ & Motor neurons & $\begin{array}{l}\text { Neurofilament misregulation, } \\
\text { Neurite degeneration, } \\
\text { Mutant SOD1 aggregates }\end{array}$ & Chen et al., 2014 \\
\hline ALS & SOD1A4V & Retroviral & Motor neurons & $\begin{array}{l}\text { Survival reduction, } \\
\text { Transcriptional change, } \\
\text { Mitochondrial defects, } \\
\text { Activation of ER stress, } \\
\text { Unfolded protein response }\end{array}$ & $\begin{array}{l}\text { Kiskinis et al., } \\
2014\end{array}$ \\
\hline ALS & SOD1A4V & Retroviral & Motor neurons & $\begin{array}{l}\text { Hyperexcitability, } \\
\text { Loss of voltage-gated currents } \\
\left(\mathrm{K}^{+}\right)\end{array}$ & $\begin{array}{l}\text { Wainger et al., } \\
2014\end{array}$ \\
\hline ALS & TDP-43 $13337 \mathrm{~V}$ & Retroviral & Motor neurons & $\begin{array}{l}\text { Survival reduction, } \\
\text { TDP-43 aggregates, } \\
\text { Vulnerability to PI3K inhibition }\end{array}$ & Bilican et al., 2012 \\
\hline ALS & TDP-43M337V & Retroviral & Astrocytes/Motor neurons & $\begin{array}{l}\text { Astrocytes: } \\
\text { Survival reduction, } \\
\text { Increased insoluble TDP-43, } \\
\text { Cytoplasmic mislocalization of } \\
\text { TDP-43 }\end{array}$ & Serio et al., 2013 \\
\hline ALS & TDP-43 ${ }^{\mathrm{M} 337 \mathrm{~V}}$ & Retroviral & Motor neurons & $\begin{array}{l}\text { Hyperexcitability (early stage), } \\
\text { Hypoexcitability (late stage), } \\
\text { Loss of synaptic activity, } \\
\text { Loss of voltage-gated currents } \\
\left(\mathrm{Na}^{+}\right)\end{array}$ & Devlin et al., 2015 \\
\hline ALS & $\begin{array}{l}\text { FUS } \\
\text { Fus11FS } \\
\text { FUS17Q }^{\mathrm{H} 517}\end{array}$ & Retroviral & Motor neurons & Hyperexcitability & $\begin{array}{l}\text { Wainger et al., } \\
2014\end{array}$ \\
\hline ALS & $\begin{array}{l}\text { FUS }{ }^{R 521 L} \\
\text { FUS }^{R 521 C} \\
\text { FUS }^{\text {R495QfsX527 }}\end{array}$ & Retroviral & Motor neurons & $\begin{array}{l}\text { Hypoexcitability, } \\
\text { Decreased synaptic activity, } \\
\text { Lower sodium to potassium } \\
\left(\mathrm{Na}^{+} / \mathrm{K}^{+}\right) \text {ratios }\end{array}$ & $\begin{array}{l}\text { Naujock et al., } \\
2016\end{array}$ \\
\hline ALS & FUS ${ }^{P 525 L}$ & Episomal & Motor neurons & $\begin{array}{l}\text { Cytoplasmic FUS localization, } \\
\text { FUS aggregation }\end{array}$ & Liu et al., 2015 \\
\hline ALS & FUS ${ }^{H 517 D}$ & Episomal & Motor neurons & $\begin{array}{l}\text { Cytoplasmic FUS localization, } \\
\text { FUS aggregation, } \\
\text { Cell death, } \\
\text { Aberrant gene expression and } \\
\text { splicing }\end{array}$ & $\begin{array}{l}\text { Ichiyanagi et al., } \\
2016\end{array}$ \\
\hline
\end{tabular}


TABLE 1 | Continued

\begin{tabular}{|c|c|c|c|c|c|}
\hline Disease & Gene mutation & $\begin{array}{l}\text { Reprogramming } \\
\text { strategy }\end{array}$ & $\begin{array}{l}\text { iPSC-derived cell } \\
\text { subtype }\end{array}$ & ALS/FTD phenotype & References \\
\hline ALS & $\begin{array}{l}\text { FUS R521C } \\
\text { FUS } \\
\text { FU95Qfs527 } \\
\text { FUsp502Thr^27 }\end{array}$ & Lentiviral & Motor neurons & $\begin{array}{l}\text { Cytoplasmic FUS localization, } \\
\text { FUS aggregation, } \\
\text { Cell death }\end{array}$ & Higelin et al., 2016 \\
\hline ALS & $\begin{array}{l}\text { FUS }^{R 514 S} \\
\text { FUS }^{R 521 C} \\
\text { FUS }\end{array}$ & Lentiviral & Motor neurons & $\begin{array}{l}\text { Cytoplasmic FUS localization, } \\
\text { FUS aggregation, } \\
\text { Cell vulnerability }\end{array}$ & Lenzi et al., 2015 \\
\hline ALS & $\begin{array}{l}\text { FUS } \\
\text { FUS21H } \\
\text { F525L }\end{array}$ & Sendai viral & Motor neurons & $\begin{array}{l}\text { Cytoplasmic FUS localization, } \\
\text { Hypoexcitability, } \\
\text { Decreased synaptic activity, } \\
\text { Axonal transport defects }\end{array}$ & Guo et al., 2017 \\
\hline ALS & C9ORF72 & Sendai viral & Motor neuorns & $\begin{array}{l}\text { Cell death, } \\
\text { Abnormal protein aggregation, } \\
\text { and stress granule formation, } \\
\text { Increased ER stress, } \\
\text { Reduced mitochondrial } \\
\text { membrane potential, } \\
\text { p62 accumulation }\end{array}$ & $\begin{array}{l}\text { Dafinca et al., } \\
2016\end{array}$ \\
\hline ALS & C9ORF72 & Episomal & Motor neurons & $\begin{array}{l}\text { Cell vulnerability, } \\
\text { DNA damage }\end{array}$ & $\begin{array}{l}\text { Lopez-Gonzalez } \\
\text { et al., } 2016\end{array}$ \\
\hline ALS & C9ORF72 & Retroviral & Motor neurons & Hyperexcitability & $\begin{array}{l}\text { Wainger et al., } \\
2014\end{array}$ \\
\hline ALS & C9ORF72 & Retroviral & Motor neurons & $\begin{array}{l}\text { Hyperexcitability (early stage), } \\
\text { Hypoexcitability (late stage), } \\
\text { Loss of synaptic activity, } \\
\text { Loss of voltage-gated currents } \\
\left(\mathrm{K}^{+} / \mathrm{Na}^{+}\right)\end{array}$ & Devlin et al., 2015 \\
\hline ALS & C9ORF72 & Episomal & Motor neurons & $\begin{array}{l}\text { RNA foci, } \\
\text { Transcriptional changes }\end{array}$ & Sareen et al., 2013 \\
\hline ALS & C9ORF72 & Retroviral & Neurons & $\begin{array}{l}\text { RNA foci, } \\
\text { RAN translation products, } \\
\text { Vulnerability to inhibition of } \\
\text { autophagy, } \\
\text { p62 accumulation }\end{array}$ & $\begin{array}{l}\text { Almeida et al., } \\
2013\end{array}$ \\
\hline ALS & C9ORF72 & Not mentioned & Motor neurons & $\begin{array}{l}\text { DPRs, } \\
\text { Cell-to-cell transmission of } \\
\text { DPRs }\end{array}$ & $\begin{array}{l}\text { Westergard et al., } \\
2016\end{array}$ \\
\hline ALS & C9ORF72 & Retroviral & Motor neurons & Modulation of actin dynamics & $\begin{array}{l}\text { Sivadasan et al., } \\
2016\end{array}$ \\
\hline ALS/FTD & C9ORF72 & Lentiviral & iNeurons & Autophagy impairment & $\begin{array}{l}\text { Webster et al., } \\
2016\end{array}$ \\
\hline
\end{tabular}


TABLE 1 | Continued

\begin{tabular}{|c|c|c|c|c|c|}
\hline Disease & Gene mutation & $\begin{array}{l}\text { Reprogramming } \\
\text { strategy }\end{array}$ & $\begin{array}{l}\text { iPSC-derived cell } \\
\text { subtype }\end{array}$ & ALS/FTD phenotype & References \\
\hline ALS & C9ORF72 & Lentiviral/Episomal & Astrocyte/Motor neurons & $\begin{array}{l}\text { Abnormal protein aggregation, } \\
\text { p62 accumulation }\end{array}$ & Madill et al., 2017 \\
\hline FTD & C9ORF72 & Episomal & Cortical neurons & $\begin{array}{l}\text { Nucleocytoplasmic transport } \\
\text { defect }\end{array}$ & $\begin{array}{l}\text { Freibaum et al., } \\
2015\end{array}$ \\
\hline ALS & C9ORF72 & Retroviral & Neurons & $\begin{array}{l}\text { Nucleocytoplasmic transport } \\
\text { defect }\end{array}$ & Zhang et al., 2015 \\
\hline ALS & VAPB $^{P 56 S}$ & Retroviral & Motor neurons & $\begin{array}{l}\text { Reduced expression levels of } \\
\text { VAPB }\end{array}$ & $\begin{array}{l}\text { Mitne-Neto et al., } \\
2011\end{array}$ \\
\hline ALS & Sporadic ALS & Unknown & Motor neurons & TDP-43 aggregates & $\begin{array}{l}\text { Burkhardt et al., } \\
2013\end{array}$ \\
\hline ALS & Sporadic ALS & Lentiviral & Motor neurons & Aberrant gene expression & Alves et al., 2015 \\
\hline ALS & Sporadic ALS & Sendai viral & Astrocytes & $\begin{array}{l}\text { Disorganized neurofilaments, } \\
\text { Aggregated ubiquitin, } \\
\text { Synaptic defects }\end{array}$ & Qian et al., 2017 \\
\hline FTD & TAU ${ }^{A 152 T}$ & Retroviral & Neurons & $\begin{array}{l}\text { Increased tau fragmentation, } \\
\text { Increased tau phosphorylation }\end{array}$ & Fong et al., 2013 \\
\hline FTD & $\mathrm{GRN}^{\mathrm{S116X}}$ & Retroviral & Neurons /Microglia & $\begin{array}{l}\text { PGRN haploinsufficiency, } \\
\text { Vulnerability to ER stress, } \\
\text { Vulnerability to inhibition of } \\
\text { proteasome }\end{array}$ & $\begin{array}{l}\text { Almeida et al., } \\
2012\end{array}$ \\
\hline FTD & GRN null & Retroviral & $\begin{array}{l}\text { Cortical neurons /Motor } \\
\text { neurons }\end{array}$ & $\begin{array}{l}\text { Inefficient cortical neuron } \\
\text { formation } \\
\text { PGRN haploinsufficiency } \\
\text { Transcriptional changes }\end{array}$ & $\begin{array}{l}\text { Raitano et al., } \\
2015\end{array}$ \\
\hline
\end{tabular}

opportunities. Compared with other model systems, there are a number of advantages of the iPSC model system. First, it gives the researcher the opportunity to model ALS with no need to overexpress the transgene with the disease-causing mutation. Second, gene editing technologies, such as CRISPR/Cas9, make it possible to correct these ALS-causing mutations in the same patient-derived iPSCs. This creates an isogenic control with exactly the same genetic background as the patient and makes it also possible to search for disease modifiers in ALS/FTD (Van Damme et al., 2017). Third, the iPSC technology enables researchers to investigate sporadic ALS cases in the laboratory. This has never been possible with other model systems before. Fourth, it allows researchers to investigate human diseases by using patient material to create different cell types. Especially for neurodegenerative diseases, patient-derived neurons are a new research tool which was unavailable before the invention of the iPSC technology. Finally, the constant improvements of differentiation protocols gives the possibility to differentiate iPSCs into many different cell (sub)types (lower motor neurons, upper motor neurons, astrocytes, oligodendrocytes, cortical neurons, ...), which allows researchers to investigate the different cell types involved in the disease process or to study the dynamics between the different cell types (Emdad et al., 2012; Maury et al., 2014; Douvaras et al., 2016). The major drawback of this model system is the in vitro approach. As a consequence, crossvalidation in other in vivo systems and/or in patient material remains crucial (Van Damme et al., 2017). Moreover, the costs of the iPSC model system are high compared to some other model systems. However, the valuable output of this relatively new model system is promising and could be very useful in basic research.

\section{Modeling of ALS in a Dish SOD1}

In 2014, two back-to-back studies were published which used novel in vitro models for ALS by generating iPSC-derived motor neurons from patients carrying a SOD $1^{\mathrm{A} 4 \mathrm{~V}}$ or a SOD $1^{\mathrm{D} 90 \mathrm{~A}}$ mutation (Chen et al., 2014; Kiskinis et al., 2014). In each study, the authors used genetic correction of both of these mutations as isogenic controls (Chen et al., 2014; Kiskinis et al., 2014). Both studies reported a high ratio of electrophysiologically active motor neurons differentiated from these iPSCs (Chen et al., 2014; Kiskinis et al., 2014). These motor neurons also recapitulated the spontaneous and progressive decrease in cell viability observed in humans (Chen et al., 2014; Kiskinis et al., 


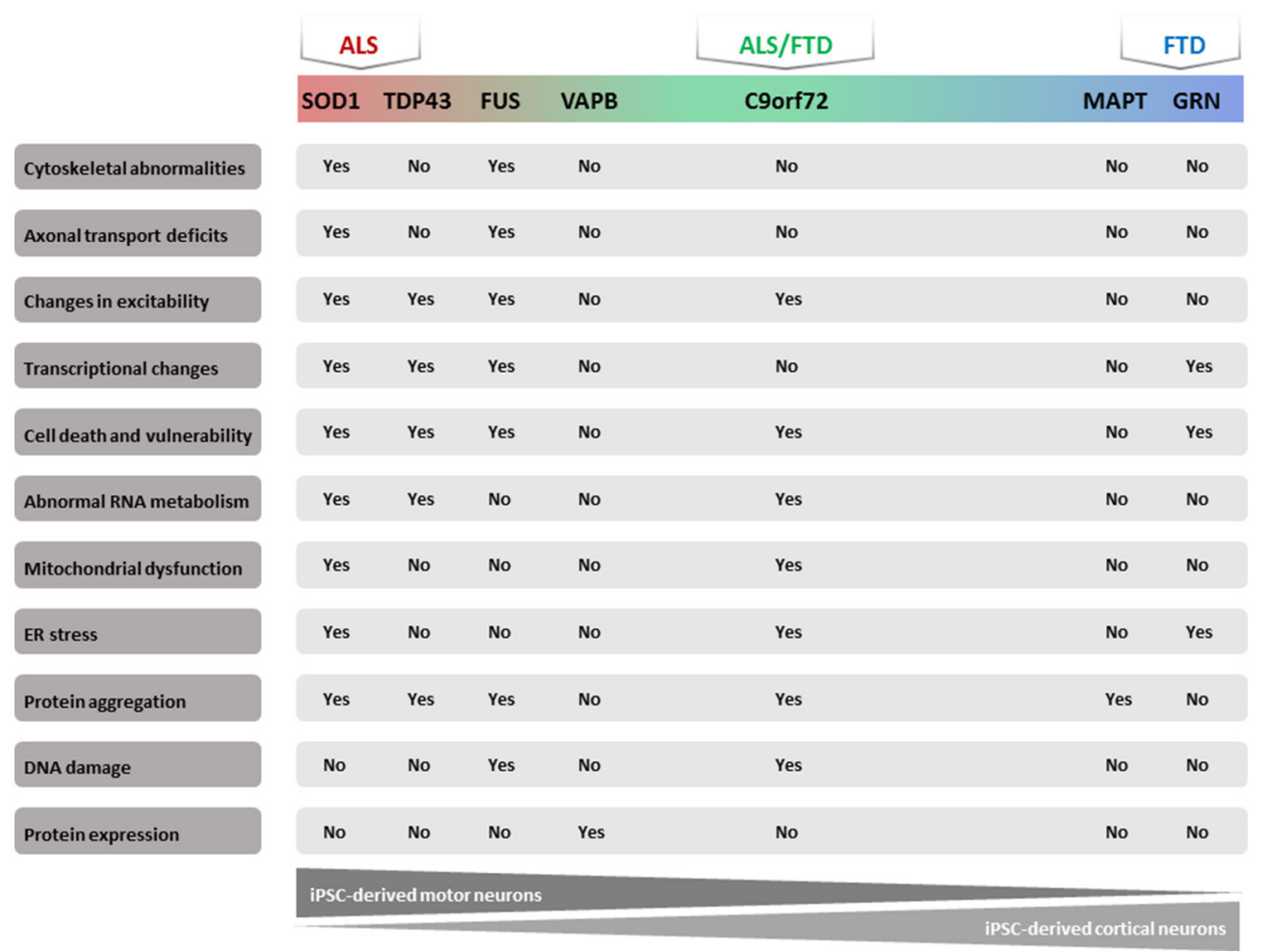

FIGURE 1 | Major phenotypes in ALS/FTD iPSC models. Summary of observed phenotypes from motor neurons or cortical neurons derived from ALS/FTD patients.

2014). Additionally, ALS-related morphological changes were observed in vitro, including a reduction in soma size and an altered dendrite length (Chen et al., 2014). This phenotype was linked to the dysregulation and aggregation of neurofilaments, an event that preceded the occurrence of neuronal apoptosis (Chen et al., 2014). RNA sequencing showed that several genes were misregulated in the patient-derived motor neurons in comparison to isogenic controls. These included transcripts related to cytoskeletal organization, mitochondrial function and structure, and protein translation (Kiskinis et al., 2014). Furthermore, the unfolded protein response was activated (Kaus and Sareen, 2015). Moreover, ER stress occurred in SOD $1^{\mathrm{A} 4 \mathrm{~V}}$ motor neurons (Kiskinis et al., 2014). In another study, Wainger and colleagues used the same iPSC lines carrying the SOD1 ${ }^{\mathrm{A} 4 \mathrm{~V}}$ mutation and demonstrated that patient-derived motor neurons showed consistent hyperexcitability (Wainger et al., 2014). The authors used this disease-specific phenotype as a tool for drug screening. Retigabine, a clinically approved anticonvulsant, blocked hyperexcitability in these patient-derived motor neurons by activating subthreshold Kv7 currents. Moreover, a significantly increased survival of motor neurons was observed in this study after treatment with retigabine (Wainger et al., 2014). This study provided the rationale to start a clinical trial using retigabine in ALS patients (Noto et al., 2016). However, hypoexcitability in combination with lower $\mathrm{Na}^{+} / \mathrm{K}^{+}$ratios were observed in motor neurons from an ALS patient carrying the SOD $1^{\mathrm{D} 90 \mathrm{~A}}$ mutation (Naujock et al., 2016). In addition, this hypoexcitability could be improved by the FDA-approved drug 4-aminopyridine (4AP) which is targeting $\mathrm{K}^{+}$currents (Naujock et al., 2016). Although it is still a debate whether hyper- or hypoexcitability plays a crucial role in ALS, it is evident that electrophysiological changes comprise a major phenotype in iPSC models, which may be a therapeutic avenue worth exploring.

\section{TARDBP}

All published studies using iPSCs derived motor neurons from mutant TARDBP patients reported some significant ALS-related pathological features, including motor neuron degeneration and accumulation of insoluble TDP-43 protein (Egawa et al., 2012).

The research group of Chandran first described a human motor neuron model derived from iPSCs from an ALS patient carrying the TDP-43 ${ }^{\mathrm{M} 337 \mathrm{~V}}$ mutation (Egawa et al., 2012). The functional maturation of motor neurons was not affected by the mutation. However, the survival of these neurons was significantly decreased. Furthermore, these TDP- $43^{\mathrm{M} 337 \mathrm{~V}}$ motor neurons also showed an increased level of soluble and detergentresistant TDP-43 compared to healthy control lines. In addition, they also demonstrated that these neurons were more susceptible to inhibition of phosphoinositide 3-kinase (PI3K), while no abnormalities in response to inhibition of mitogen-activated protein kinase (MAPK) or ER stress induction were observed (Egawa et al., 2012). As some neurotropic factors rely on the PI3K pathway, this result supports the importance of neuronal trophic support. In a later publication, this research group used the same iPSC line (TDP- $43^{\mathrm{M} 337 \mathrm{~V}}$ ) to generate almost pure astrocytes in order to investigate the astrocyte pathology in ALS 
(Serio et al., 2013). Astrocytes from TDP-43 ${ }^{\mathrm{M} 337 \mathrm{~V}}$ iPSCs showed cytoplasmic mislocalization of soluble TDP-43 (Serio et al., 2013). In comparison to wild type astrocytes, TDP- $43^{\mathrm{M} 337 \mathrm{~V}}$ astrocytes showed a cumulative risk of death under basal conditions. However, these cells did not show increased levels of detergent resistant TDP-43, which is different from iPSC-derived motor neurons (Serio et al., 2013). Moreover, the authors used an isogenic control to confirm the observations linking TDP-43 cytoplasmic localization to survival in astrocytes (Serio et al., 2013). In addition, coculturing motor neurons and astrocytes showed that mutant TDP-43 iPSC-derived astrocytes had no effect on motor neuron survival (Serio et al., 2013). Conversely, murine glia overexpressing mutant SOD1 were shown to be toxic to cocultured human iPSC-derived motor neurons (Hedlund and Isacson, 2008).

Egawa and colleagues generated several iPSC lines from three ALS patients with different TDP-43 mutations (Q343R, M337V, and G298S). The authors did not observe that TDP43 mutations impaired motor neuron maturation (Egawa et al., 2012). However, insoluble TDP-43 inclusions were found in these neurons (Egawa et al., 2012). In contrast to a previous report from Bilican et al. (2012), TDP-43 mRNA levels were higher in mutant cell lines compared to control lines. To explain this discrepancy, the authors suggested that the variation between different iPSC lines and the different purity of motor neurons could account for this difference (Bilican et al., 2012). The study also identified decreased neurite lengths and a higher vulnerability to oxidative stress in the mutant motor neurons. Interestingly, in their drug screening assay, anacardic acid, which is a histone acetyltransferase, was demonstrated as an efficient drug candidate which could reverse the disease-related phenotypes (Egawa et al., 2012).

Serio et al. focused on the physiological aspect of motor neurons carrying the TDP- $43^{\mathrm{M} 337 \mathrm{~V}}$ mutation by using the same iPSC lines used for generating astrocytes. Hyperexcitability at early stages followed by a progressive loss in action potential output and synaptic activity were shown in the patient-derived motor neurons. As mentioned above, this hyperexcitability phenotype is shared with iPSC-derived motor neurons from patients with SOD1 mutations (Serio et al., 2013).

The group of Gao derived neuronal cultures from iPSCs of an FTD patient, who also showed ALS symptoms, containing an A90V mutation in TDP-43 (Zhang et al., 2013). The A90V mutation is a rare mutation which was identified as a risk factor for both ALS and FTD (Zhang et al., 2013). The disease duration in a patient with this mutation can be more than two decades from the time of diagnosis, which is a particularly long disease duration for ALS. Mislocalized cytoplasmic TDP43 and decreased expression of total TDP-43 after treatment with staurosporine were observed in the neurons derived from these patient iPSCs (Zhang et al., 2013). Interestingly, the neurons generated from a patient carrying the M337V mutation showed increased TDP-43 aggregates in the absence of any stress (Bilican et al., 2012). This suggested a cell-autonomous toxicity in TDP-43 ${ }^{\mathrm{M} 337 \mathrm{~V}}$ lines. In addition, decreased miR-9 expression was shown in neurons with $\mathrm{A} 90 \mathrm{~V}$, as well as with the M337V mutation in TDP-43 (Zhang et al., 2013). Since
miRNA misregulation has also been reported in FUS-ALS, this could reveal a common downstream process in different disease subtypes that are caused by mutations in different ALS-associated genes (Bilican et al., 2012; Zhang et al., 2013).

\section{FUS}

Over the past few years, several FUS-iPSC models have been generated. One publication described motor neuron cultures derived from two FUS-iPSC lines carrying a frameshift mutation at residue 511 (M511FS) or a H517Q point mutation. These motor neurons were shown to be hyperexcitable (Wainger et al., 2014). Conversely, another research group reported hypoexcitability in FUS lines carrying a point mutation (R521L or R521C) and a frame shift mutation (R495QfsX527) (Naujock et al., 2016).

Another study demonstrated cytoplasmic mislocalization and the formation of FUS aggregates in differentiated motor neurons from a patient carrying a P525L mutation (Liu et al., 2015). Similarly, motor neurons derived from ALS patients carrying a H517D mutation in FUS showed cytoplasmic FUS localization and stress granule formation under stress conditions. Moreover, exon array analysis combined with CLIP-seq data revealed aberrant gene expression and/or splicing patterns in patient-derived motor neuron precursor cells (Ichiyanagi et al., 2016). The cytoplasmic FUS mislocalisation was also observed in motor neurons derived from patients with a benign R521C mutation and the more severe R495Qfs527 and Asp502Thrfs*27 frameshift mutations (Higelin et al., 2016). Moreover, the amount of cytoplasmic FUS accumulation correlated with the clinical severity of the underlying FUS mutation (Higelin et al., 2016). Furthermore, the severity of the FUS mutation, as well as neuronal aging, also induced spontaneous formation of cytoplasmic FUS inclusions (Higelin et al., 2016). These aggregates showed typical characteristics of FUS-ALS including the presence of methylated FUS (Higelin et al., 2016). Additionally, higher vulnerability and increased DNA damage were observed in patient-derived motor neurons after irradiation (Higelin et al., 2016).

Lenzi et al. used iPSCs derived from patient fibroblasts carrying a R514S or a R521C mutation in combination with iPSC cells, in which the P525L mutation was introduced using transcription activator-like effector nucleases (TALENs)-directed mutagenesis (Lenzi et al., 2015), to differentiate into motor neurons. The presence of mutant FUS resulted in the aberrant localization and recruitment of FUS into stress granules (SGs). However, this only occurred upon induction of stress and the incorporation into SGs was proportional to the amount of cytoplasmic FUS (Lenzi et al., 2015).

We recently generated and characterized iPSCs from ALS patients with $\mathrm{R} 521 \mathrm{H}$ and $\mathrm{P} 525 \mathrm{~L}$ mutations in FUS. Patientderived motor neurons showed typical cytoplasmic FUS pathology, hypo-excitability, as well as progressive axonal transport defects. Cytoplasmic mislocalization of FUS was most pronounced in the $\mathrm{P} 525 \mathrm{~L}$ mutant line and was not specific for motor neurons. Both cytoplasmic FUS pathology and axonal transport defects were rescued by "clustered regularly interspaced short palindromic repeats” (CRISPR)/Cas9-mediated 
genetic correction of the FUS mutation in patient-derived iPSCs. Furthermore, we could rescue the defects pharmacologically by histone deacetylase 6 (HDAC6) inhibition and by genetic silencing of HDAC6, which suggests that this could become a new therapeutic strategy for ALS (Guo et al., 2017).

\section{C9ORF72}

The immense expansion of $\mathrm{G}_{4} \mathrm{C}_{2}$ repeats in C9ORF72 makes it particularly difficult to develop good animal models. As a consequence, iPSCs could offer the ideal solution for modeling in vitro the effect of the hexanucleotide expansion in C9ORF72. Three potential mechanisms have been proposed to explain the pathogenic role of the hexanucleotide expansion in C9ORF72. First, a reduction in the expression level of C9ORF72 observed in some C9ORF72 patients has led to the hypothesis that a loss of C9ORF72 may contribute to the disease (Waite et al., 2014). Second, the accumulation of RNA foci containing the hexanucleotide expansion found in the brain and spinal cords of patients suggested a disease mechanism, involving a toxic gain of function (DeJesus-Hernandez et al., 2011). This is thought to be mediated by repeat-containing RNA that can potentially bind RNA-binding proteins (DeJesus-Hernandez et al., 2011). Third, both the sense and antisense repeat RNAs can undergo repeat-associated non-ATG (RAN) translation, resulting in the formation of a series of potentially toxic DPRs (Gendron et al., 2013; Zu et al., 2013). RAN translation can occur from both sense and antisense expansion transcripts, resulting in the expression of six RAN proteins (antisense: Pro-Arg, Pro-Ala, Gly-Pro; and sense: Gly-Ala, Gly-Arg, Gly-Pro). These DPRs form neuronal cytoplasmic and intranuclear inclusion in patients carrying the expansion (Gendron et al., 2013; Zu et al., 2013). However, the exact contribution of each of these mechanisms to neuronal death is not yet clear.

Several studies on C9ORF72 patient iPSCs have shown the potential of iPSCs in recapitulating the major pathological signatures of the disease. In 2013, three groups generated iPSCs from ALS/FTD patients carrying the C9ORF72 mutation (Almeida et al., 2013; Donnelly et al., 2013; Sareen et al., 2013), in which several aspects of C9ORF72-related pathology were observed. RNA foci were detected in patient-derived neurons and the sequestration of RNA binding proteins, including ADARB2, hnRNPA1, and Pur- $\alpha$, by the expanded RNA repeat was observed (Donnelly et al., 2013; Sareen et al., 2013). Dipeptide RAN pathology was also described in neurons derived from C9ORF72 patients (Almeida et al., 2013; Donnelly et al., 2013). Interestingly, Westergard and collaborators demonstrated, by using C9ORF72 iPSCs-derived spinal motor neurons (sMNs), evidence for cell-to-cell spreading of DPRs in a co-culture system of control and C9ORF72 iPSC-derived sMNs (Westergard et al., 2016). In terms of haploinsufficiency, C9ORF72 expression was observed to be reduced in patient-derived neurons compared to controls (Almeida et al., 2013; Donnelly et al., 2013), whereas in the study of Sareen et al., no change in C9ORF72 expression was found in patient-derived motor neurons (Sareen et al., 2013). From a therapeutic point of view, two studies investigated antisense oligonucleotides (ASOs) in C9ORF72 iPSCs-derived neurons (Donnelly et al., 2013; Sareen et al., 2013). Interestingly, after ASO treatment, the toxicity associated with the endogenous C9ORF72 mutation was abrogated (Donnelly et al., 2013; Sareen et al., 2013). Moreover, the C9ORF72 knockdown with ASOs had no impact on iPSCs-derived neuron survival, leading the authors to argue against a loss of function mechanism as the major cause of C9ORF72 pathology and toxicity seen in iPSCs (Donnelly et al., 2013; Sareen et al., 2013).

Aside from recapitulating the major pathological hallmarks of the disease, iPSC-based platforms have also revealed novel mechanisms of neurodegeneration. Two independent studies showed impaired nucleocytoplasmic transport in patient-derived neurons (Freibaum et al., 2015; Zhang et al., 2015). Zhang and colleagues showed that RanGAP1, a key regulator of nucleocytoplasmic transport, physically interacted with the expanded RNA foci and was mislocalized in the cytoplasm of C9ORF72 iPSC-derived neurons. In addition, the authors also showed that nuclear import of proteins and RNAs was impaired in patient iPSC-derived neurons, and these deficits were rescued by antisense oligonucleotides targeting the C9ORF72 RNA (Zhang et al., 2015). Similarly, Freibaum and colleagues observed impaired nucleocytoplasmic transport in C9ORF72 iPSC-derived neurons. Furthermore, investigation of the total RNA distribution revealed increased nuclear RNA retention in C9ORF72 iPSC-derived cortical neurons (Freibaum et al., 2015).

Vulnerability to ER and oxidative stress was also investigated in C9ORF72 iPSCs-derived motor neurons. Dafinca and colleagues showed that C9ORF72 iPSC-derived motor neurons exhibited loss of $\mathrm{Ca}^{2+}$ homeostasis, which was associated with a decrease in mitochondrial potential and an increase in ER stress (Dafinca et al., 2016). Moreover, an increase of yH2AX, a marker of DNA damage, was observed in C9ORF72 iPSCsderived motor neurons in an age-dependent manner (LopezGonzalez et al., 2016). Interestingly, the ectopic expression of the DPR protein $(\mathrm{GR})_{80}$, but not $(\mathrm{GA})_{80}$, increased DNA damage in iPSC-derived control neurons. Pharmacological or genetic reduction of oxidative stress partially reduced DNA damage in C9ORF72-derived motor neurons suggesting that oxidative stress could play an important role in the disease mechanism (Lopez-Gonzalez et al., 2016).

Several studies performed electrophysiology on C9ORF72 iPSC-derived neurons to investigate possible impairments in excitability, as observed in C9ORF72 patients (Williams et al., 2013; Geevasinga et al., 2015). Using multi-electrode array and patch clamp recordings, Wainger and colleagues showed network hyperexcitability in C9ORF72 iPSC-derived motor neurons (Wainger et al., 2014). In direct contrast, another group showed a diminished capacity to fire continuous spikes upon depolarization in C9ORF72 iPSC-derived motor neurons compared to control motor neurons (Sareen et al., 2013). Moreover, C9ORF72 iPSC-derived motor neurons showed altered expression of genes involved in membrane excitability, including the delayed rectifier potassium channel (KCNQ3) which is consistent with hypoexcitability (Sareen et al., 2013). As indicated before, these divergent findings can possibly be explained by the temporal analysis of C9ORF72 iPSC-derived motor neuron excitability as performed by Devlin and colleagues (Devlin et al., 2015). This research group demonstrated that 
patient iPSC-derived motor neurons displayed an intrinsic hyperexcitability at early time points (21-28 days in culture), followed by a loss in action potential output and synaptic activity in cells maintained for up to 70 days in culture. This loss of functional output was correlated to a progressive loss of both voltage-activated $\mathrm{Na}^{+}$and $\mathrm{K}^{+}$currents (Devlin et al., 2015). Further experimental evidence is required to determine whether the altered excitability observed in C9ORF72 motor neurons plays indeed a pathogenic role in ALS or whether it is related to a homeostatic response to specific culture conditions.

Non-cell autonomous toxicity mechanism were also investigated using patient iPSCs-derived cells. Mayer and colleagues showed that C9ORF72 iPSC-derived astrocytes were toxic when co-cultured with motor neurons. This strongly indicates that astrocytes play an important role in the C9ORF72-mediated pathology (Meyer et al., 2014). Similarly, oligodendrocytes from C9ORF72 patients, obtained through different reprogramming protocols, induced motor neuron death both through conditioned media as well as in co-cultures (Ferraiuolo et al., 2016).

Several studies provided evidence for a role of C9ORF72 in important cellular functions suggesting that a loss of function of C9ORF72 could eventually contribute to the disease process. C9ORF72 is homologous to members of the DENN (differentially expressed in normal and neoplastic cells) domain containing protein family and is predicted to function as a guaninenucleotide exchange factor for several Rab proteins (Levine et al., 2013). Consistent with the prediction of its function, C9ORF72 protein was found to colocalize with Rab proteins and to be involved in endosomal trafficking and autophagy (Farg et al., 2014). Subsequently, several studies showed a role of C9ORF72 in the induction of autophagy (Sellier et al., 2016; Sullivan et al., 2016; Webster et al., 2016; Yang et al., 2016) and reduction in the basal autophagy levels in C9ORF72 patient-derived neurons (Webster et al., 2016). Moreover, increased level of p62, an autophagy marker, were observed in C9ORF72 iPSCs-derived neurons (Almeida et al., 2013; Dafinca et al., 2016), reminiscent of the p62 pathology observed in C9ORF72 patients (Mackenzie et al., 2014). Recently, a study in human iPSC-derived neurons revealed that C9ORF72 modulates cytoskeletal actin dynamics via phosphorylation of cofilin and shRNA mediated knockdown of C9ORF72 resulted in axonal outgrowth deficits (Sivadasan et al., 2016).

Taken together, the above studies used iPSC technology to establish in vitro models for C9ORF72-ALS. Apart from providing novel insights into the disease mechanisms, antisense strategies were suggested as a promising treatment option to counteract the negative impact of the hexanucleotide repeat expansions in C9ORF72.

\section{VAPB}

A mutation in the "vesicle-associated membrane proteinassociated protein $B$ and C" (VAPB) gene is a rare cause of ALS (subtype 8), and has an autosomal dominant mode of inheritance. Mitne-Neto and colleagues generated iPSCs from an ALS patient with a P56S mutation in VAPB, as well as from their non-carrier siblings. These cells could be differentiated into mature motor neuron. No obvious alterations in VAPB distribution were detected in patient-derived cells. Similarly, no aggregates were found in patient cells, even after inducing stress in the cells using the proteasome inhibitor MG132. However, a significant decrease in VAPB protein level was observed in patient-derived motor neurons and the reduction was $\sim 50 \%$ compared to controls (Mitne-Neto et al., 2011).

\section{Sporadic ALS}

Although sporadic forms of ALS account for $90 \%$ of total ALS cases, it is much more difficult to model this form of the disease as the exact causes are unknown. As already indicated, iPSC technology could give us the unique opportunity to mimic some pathological and electrophysiological phenotypes in vitro.

The first publication on a sporadic ALS iPSC model was from Burkhardt and colleagues. Skin fibroblasts were reprogrammed from 16 sporadic ALS patients, 8 familial ALS patients and 10 healthy persons as controls. Nearly 100 iPSC clones from 34 patients were analyzed. Spontaneous TDP-43 pathology was observed in iPSC-derived motor neurons from $20 \%$ of the sporadic ALS patients (Burkhardt et al., 2013). These TDP-43 aggregates were hyperphosphorylated, but no ubiquitination was observed. Additionally, the TDP-43 aggregates in motor neurons differentiated from iPSC were validated in anterior horn neurons of spinal cord and cortical neurons from one of the patients who donated the fibroblasts. Interestingly, this was the first time that a pathological phenotype found in iPSC-motor neurons could be linked to post mortem tissue from the same ALS patient, thus validating iPSC-derived models as a powerful tool.

iPSC-motor neurons from one sporadic ALS patient were also used for a drug screening assay (Burkhardt et al., 2013). In total, 1757 bioactive compounds were tested on these neurons and the percentage of neurons containing TDP-43 aggregates was used as the criterion to analyze the efficiency of these compounds. After two rounds of selection, four classes of compounds, including cyclin-dependent kinase inhibitors, Digoxin, Lanatoside C, and Proscillaridin A, were obtained that reduced in a dose-dependent manner the percentage of cells with TDP-43 aggregates (Burkhardt et al., 2013). These findings rely on a prominent role of protein aggregation in the progression of neuronal degeneration in ALS (Burkhardt et al., 2013). Another large gene profiling experiment starting from differentiated motor neurons from sporadic ALS patients showed that most dysregulated genes were related to mitochondrial function. As a consequence, this result highlights mitochondrial participation in motor neuron degeneration and indicates that cell autonomous mechanisms could be associated with sporadic ALS (Alves et al., 2015).

\section{Modeling FTD Using iPSCs MAPT}

From a pathological point of view, there are three main subtypes of FTD: FTD-TDP, FTD-FUS, and FTD-tau. Tau pathology is also a hallmark of Alzheimer's disease and progressive supranuclear palsy (Xia and Dickerson, 2017). FTD-tau is caused by mutations in the MAPT gene which encodes the tau protein (Rovelet-Lecrux et al., 2010; Ling et al., 2013). MAPT transcripts are diverse and 
widely expressed in the nervous system. The expression level of these transcripts depends on the neuronal maturation stage and the neuronal subtype. Tau is a microtubule-associated protein which is highly expressed in neurons (Rovelet-Lecrux et al., 2010).

Fong and colleagues generated iPSC from an individual carrying a heterozygous A152T mutation in tau (Fong et al., 2013). By using zinc-finger nuclease-mediated gene editing, they developed two isogenic iPSC lines: one with the point mutation corrected, and one with a homozygous point mutation. These iPSCs were successfully differentiated into neurons which was confirmed by a "microtubule-associated protein 2" (MAP2) staining (Fong et al., 2013). The survival of these neurons was affected by the point mutation (Fong et al., 2013). Axonal degeneration and caspase-cleaved tau fragmentation increased in severity from heterozygous to homozygous mutant lines, while corrected isogenic control lines remained normal (Fong et al., 2013). Furthermore, the amount of phospho-tau-positive neurons also increased in a dose-dependent manner. Taken together, this iPSC-derived model mimicked the tau pathology in vitro, confirmed the causal link between the tau mutation and tau pathology and helped to elucidate some of the key underlying pathogenic mechanisms.

\section{GRN}

The GRN gene encodes a progranulin precursor protein which is cleaved into different Granulins (Grns) that are glycosylated and secreted. Progranulin as well as GrnE have neurotrophic actions both in vitro and in vivo (Bhandari and Bateman, 1992; Van Damme et al., 2008). Autosomal dominant mutations in the GRN gene have been implicated in up to $25 \%$ of familial FTD cases and these mutations seem to cause the disease due to haploinsufficiency (Guven et al., 2016; Rainero et al., 2017).

To investigate the pathogenic mechanism of GRN in FTD, two research group created iPSCs from FTD patients with different mutations in GRN. Almeida and colleagues differentiated iPSCs containing a non-sense mutated GRN (S116X) into neurons and microglia (Almeida et al., 2012). The mixed postmitotic neurons expressed MAP2, vesicular glutamate transporter 1, glutamate decarboxylase and tyrosine hydroxylase. Compared to controls, no differences were observed in the neuronal differentiation of mutant cells (Almeida et al., 2012). Grns mRNA levels were significantly decreased in fibroblasts, iPSCs and iPSCderived neurons from the $\mathrm{GRN}^{\mathrm{S116X}}$ FTD patient compared to normal control and sporadic FTD patients (Almeida et al., 2012). In addition, GRN ${ }^{S 116 X}$ neurons were more sensitive to specific protein kinase inhibitors which indicates that the PI3K/Akt and MEK/MAPK signaling pathways could be involved in the molecular pathogenesis of FTD. Neither mitochondrial nor oxidative stressors increased the sensitivity of FTD patient derived neurons, implicating that these two pathway were not affected by the GRN level (Almeida et al., 2012). Both neurons from $G R N^{S 116 X}$ FTD patient and sporadic FTD patient showed vulnerability to ER stress in a GRN-independent way (Almeida et al., 2012).

We were involved in the creation of iPSCs from FTD patients

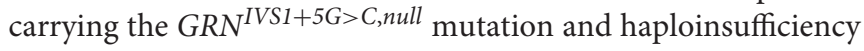

of GRN was observed in these FTD-iPSCs (Raitano et al., 2015). The iPSCs were further differentiated into cortical neurons, which are affected in FTD patients. Although neuroprogenitors could be generated without any problem, the generation of "COUP-TF-interacting protein 2" (CTIP2), forkhead box protein P2 or "T-box, brain, 1" (TBR1) positive cortical neurons was dramatically lower in FTD patient lines compared to lines from their normal family members. This was specific for cortical neurons as the FTD-iPSCs could be normally differentiated into motor neurons. After introduction of GRN cDNA into the AAVS1 locus of the FTD-iPSC line, the cortical neurogenesis defect was restored. RNA-seq data showed that genes related to the $\mathrm{Wnt} / \beta$-catenin signaling pathway were higher expressed in FTD-iPSCs compared to a corrected control line or an ESC line (Raitano et al., 2015). After treatment with IWP2, an inhibitor of active $\beta$-catenin levels, more brain lipid-binding protein- and CTIP2-positive cells were generated from the FTD patient lines. All together, these results highlight the Wnt signaling pathway as a potential therapeutic target in FTD (Raitano et al., 2015).

\section{C9ORF72}

The first iPSCs from FTD patients with C9ORF72 hexanucleotide repeats were created by Almeida and colleagues (Almeida et al., 2013). They developed several iPSC lines from two patients with C9ORF72 repeats $\left(\mathrm{G}_{4} \mathrm{C}_{2}>1,000\right.$ repeats) belonging to the same FTD family. Similar to the effect of other mutations causing ALS/FTD, the maturation process of neurons was not impaired. RNA foci were observed in fibroblasts, iPSCs, iPSC-derived neurons from the patient cell line, but not in healthy controls. RAN translational products were also found in the iPSCs-derived neurons from patients. Decreased cell viability and increased caspase- 3 activation were observed in human neurons carrying $\mathrm{G}_{4} \mathrm{C}_{2}$ repeat expansions after treatment with two different autophagy inhibitors (Webster et al., 2016). Furthermore, p62 significantly accumulated in neurons with C9ORF72 repeats, but not in neurons derived from control iPSCs of healthy persons or neurons derived from iPSCs of an FTD patient with a GRN mutation (Webster et al., 2016). These results strongly suggest an involvement of autophagy in C9ORF72-FTD.

\section{CURRENT LIMITATIONS TO IPSC TECHNOLOGY}

Although the iPSC technology has been used for modeling human diseases and drug screenings worldwide, there are still a number of limitations that should be solved. In the research area of ALS and FTD, more specific questions have to be answered in order to validate and improve this emerging tool (Figure 2).

\section{Dissimilarity among iPSC Lines}

As more and more iPSC lines are established and compared between different laboratories, large variations are discovered among different iPSC lines and, surprisingly, even between iPSC lines originating from the same donor sample. As a consequence, it is extremely important to standardize the different procedures involved in reprogramming in order to minimize these differences. 


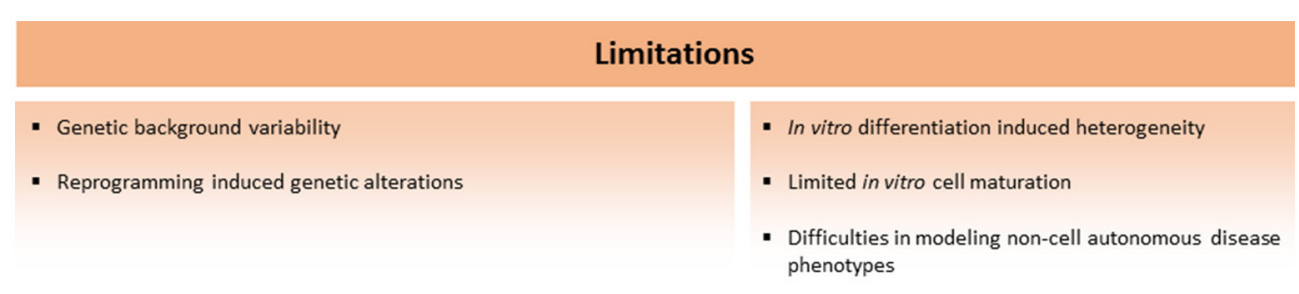

Epigenetic reprogramming

In vitro differentiation

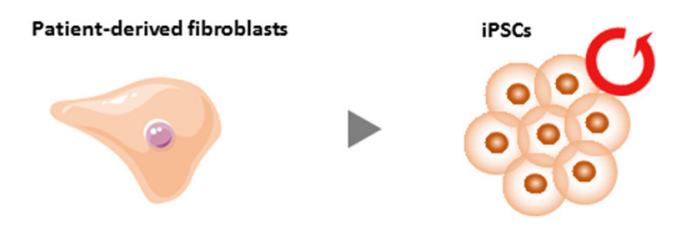

- Familial case: generation of isogenic control cell lines (CRISPR/Cas9, TALEN). Sporadic case: multiple healthy controls ( $>3$ )

- Non-integrating reprogramming techniques (oriP/EBNA1 based episomal vectors, Sendai viral vectors, microspheres)
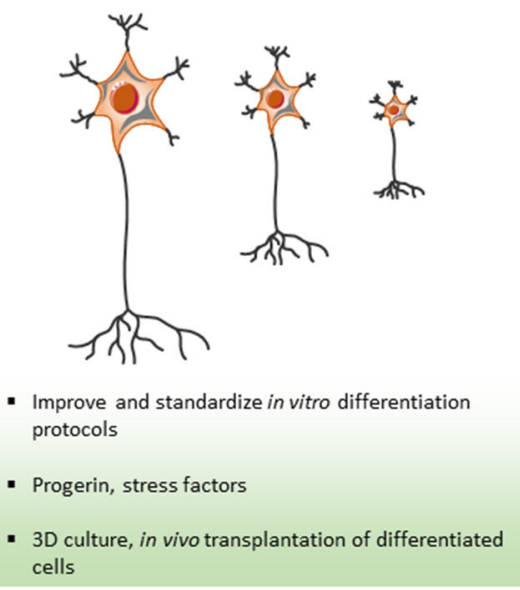

Possible solutions

FIGURE 2 | Limitations and current solutions to iPSC technology in ALS/FTD.

\section{Setting Back the Clock: The Reprogramming Process} The initial work of Shinya Yamanaka in 2007 drew global interest to iPSC disease modeling. In their first description of the reprogramming method of somatic cells, four transcription factors (Oct3/4, Sox2, Nanog, cMyc) were delivered to human fibroblasts by integrating retroviral vectors (Takahashi et al., 2007). This method is still widely used to develop iPSC lines. However, this will result in the random insertion of these transgenes into the genome. The exact effect of this random integration is unknown and genomic modifications could have an unexpected and unwanted impact on the iPSC lines. For instance, transcriptional changes of certain genes could interfere with the analysis of the phenotypes. To avoid this drawback, Cre/loxP recombination and piggyBac transposon systems have been proposed to remove the transgenes, but both of these methods are time consuming and have a low efficiency (Karow et al., 2011; Zhou and Zeng, 2013). The introduction of integration free vectors is a milestone to avoid this problem in the reprogramming process. The first integration free reprogramming method was the cloning of the reprogramming factors into oriP/EBNA1 based episomal vectors, which are gradually lost during cell proliferation ( $\mathrm{Yu}$ et al., 2009). Another method is the use of inactivated Sendai viral vectors. These are RNA virus based vectors with a high transfection efficiency, without the capability to integrate into the genome and they are also easily removed after a few cell passages. Another concern which was raised from research with mouse iPSCs is that the selection of reprogramming factors can influence the differentiation potential of iPSCs (Buganim et al., 2014). The use of the standardized integration free "Sendai Reprogramming Kit" with well-characterized reprogramming factors and protocols may help to avoid these unwanted effects (Trott et al., 2017). In addition, a novel approach was proposed recently by using microspheres conjugated with reprogramming factors for delivery into human fibroblasts (Unciti-Broceta et al., 2015). If this is a success, the use of small molecules to reprogram could be the next important step.

\section{Pluripotency}

A critical step in the procedure to obtain iPSCs is the characterization of the pluripotency potential. The final goal of the reprogramming process is to obtain iPSCs that are comparable to ESCs with respect to their pluripotency. The traditional status quo for pluripotency characterization is a combination of gene and antigen expression analysis, morphology, and capacity to differentiate in vivo. With respect to this procedure, several questions could be raised. In addition, the random inactivation of one of the $\mathrm{X}$ chromosomes (lyonization) is also a factor that could cause variation amongst female iPSC lines (Tomoda et al., 2012; Dandulakis et al., 2016). This can change the gene expression of some neuronal genes located on the X chromosome.

Analysis of teratomas has always been the golden standard for the confirmation of pluripotency (Nelakanti et al., 2015). 
However, it has been reported that even partially reprogrammed colonies can form teratomas in vivo (Baker, 2012). Therefore, more landmarks have been proposed to identify a fully reprogrammed iPSC. In theory, and to avoid these problems, a whole genome transcription and methylation analysis could provide more reliable information. In practice, this technology is expensive and is not available to every lab. As a consequence, the ideal situation would be the establishment of an international consortium collecting and storing all fully characterized iPSC lines containing all possible information for each of these established iPSC lines.

\section{Controls}

For iPSC disease modeling, the ultimate identification of disease phenotypes largely depends on the availability of reliable controls. It was shown in numerous situations that genetic background could play an important role in the disease manifestation and disease progression (Turner et al., 2017). For ALS and FTD, some causative genes have already been identified, but even for these there are huge variations in the disease process (Régal et al., 2006). It is not clear what causes these differences. However, unknown environmental factors and genetic risk factors may play a role in these dissimilarities. In order to avoid the influence of this genetic background on the disease-related phenotypes, proper controls are crucial. For the familial cases, genome editting is a promising strategy to correct point mutations or to remove pathological repeats in iPSC lines in order to create isogenic controls. Zinc finger nucleases, TALENs, as well as the more recently discovered CRISPR guided Cas9 nuclease system are the widely used technologies to perform these modification (Carroll, 2011; Beurdeley et al., 2013; Ran et al., 2013). A method based on piggyBac transposons allows seamless genome modification in patient derived iPSCs (Xie et al., 2014). The isogenic control keeps exactly the same genetic background as the mutant iPSCs. As there is still the risk of inducing off-targets effects or unwanted mutations by using these gene engineering technologies, exon sequencing and the choice of unique target sequences is crucial to minimize these drawbacks (Cho et al., 2014). In conclusion, corrected isogenic lines can be considered as the best controls for the familial type of ALS/FTD patient lines.

\section{Differences between Differentiation Methods}

Numerous neuronal subtypes exist and selective vulnerability of these different neurons to the disease process is typical for the various neurodegenerative disorders. Motor neurons are mainly degenerating in ALS, while $70 \%$ of the affected cells in FTD patients are pyramidal cortical neurons (Rowland and Shneider, 2001; Boxer and Miller, 2005; Ling et al., 2013). By using different combinations of small molecules, several methods were developed to differentiate iPSCs into motor neurons or cortical neurons, but with varying efficiencies.

\section{Identity of Motor Neurons}

According to developmental studies, motor neuron specification goes through multiple steps and results in different subtypes of motor neurons. The inner cell mass first differentiates into ectoderm. Later, the inhibition of TGF- $\beta /$ Smad signaling in combination with the enhancement of FGF and Wnt signaling triggers the specification from ectoderm to neuroectoderm (Vallier et al., 2009; Davis-Dusenbery et al., 2014; Kiecker et al., 2016). In the next step, a retinoic acid (RA) gradient and the activity of FGFs and "growth differentiation factor 11" (Gdf11) promote the neural tube pattern which results in the initial status of the central nervous system (Davis-Dusenbery et al., 2014; Maury et al., 2014). By the different regulation of CDX and HOX gene expression, motor neuron can be further specified into different subtypes (Davis-Dusenbery et al., 2014; Kiecker et al., 2016). For spinal cord motor neuron specification, "sonic hedgehog" (Shh), "bone morphogenic protein" (BMP)/TGF $\beta$ signaling, and the floor plate in the neural tube function together to trigger this specific differentiation pattern (Ribes et al., 2010).

In vitro differentiation from ESC/iPSC to motor neurons is also based on this process by triggering the different gene expression in every stage of the differentiation. The best way to generate motor neurons in vitro is to use small chemicals with different dosages at specific intervals to mimic every step of specification that takes place during development. The first description of motor neuron differentiation from human ESCs was published in 2005 and was based on RA inducing neuronal rosette formation and Shh inducing spinal cord motor neuron specification (Shin et al., 2005). This protocol results in $\mathrm{Hb}$ /Islet1 positive, functional motor neurons with about $20 \%$ efficiency. Moreover, it is a time consuming protocol which requires 33 days to achieve initial motor neurons and a much longer time in order to gain functional mature motor neurons (Shin et al., 2005). Subsequently, several modified protocols were optimized based on the original one (Sances et al., 2016). They commonly share three key phases: neuronal induction, motor neuron specification, and motor neuron maturation. SB-431542, LDN-193189, and dorsomorphin were used for inhibition of TGF $\beta / B M P$ signaling in order to trigger neuronal differentiation (Patani et al., 2011; Amoroso et al., 2013; Gouti et al., 2014; Kiskinis et al., 2014; Maury et al., 2014; Du et al., 2015). In addition, the FGF pathway and Wnt signaling were also used to promote this differentiation stage (Dimos et al., 2008; Hu et al., 2009; Patani et al., 2011; Gouti et al., 2014). Nestin, PAX6 and Sox1 expression are used to check the quality of the neuronal progenitors (Yuan et al., 2011; Tian et al., 2013; Li et al., 2017). RA is used to link the neuroprogenitor phase to the motor neuron specification phase and a combination of RA, Shh, purmorphamine or SAG were used to initiate the Shh signaling pathway which contributes to the ventralization (Lee et al., 2007; Dimos et al., 2008; Amoroso et al., 2013; Kiskinis et al., 2014; Maury et al., 2014; Qu et al., 2014). The motor neuron progenitors should be positively stained for Olig2 (Masahira et al., 2006; Li et al., 2008; Hu and Zhang, 2009; Lee et al., 2014). It was reported that $\gamma$-secretase inhibition can significantly increase the motor neuron production upon $\mathrm{SHH}$ pathway activation (Maury et al., 2014). The expression of $\mathrm{Hb} 9$ and Islet 1 expression are used as the criteria for the success of the initial motor neuron differentiation (Davis-Dusenbery et al., 2014). For the final motor neuron maturation, neurotrophic factors are applied to promote the formation of mature functional motor neurons which form 
functional synapses, that are electrophysiologically active and that can form neuromuscular junctions when co-cultured with myoblasts (Chen et al., 2014; Davis-Dusenbery et al., 2014; Sances et al., 2016).

As more and more protocols are reported, it is crucial that the criteria used to obtain and to characterize motor neurons are harmonized. This harmonization is also important for drug screening and to increase the success of translation of the results to the clinic. This could also help to obtain more convincing and reproducible results, as some findings obtained with motor neurons derived from iPSCs couldn't be replicated in different labs. This could, at least partially, be due to the different protocols using different molecules at different concentrations. For instance, the level of antioxidants present in the culture media could affect ALS-related phenotypes, as oxidative stress seems to be involved in triggering the disease process (Barber et al., 2006; Mattson and Magnus, 2006; Niedzielska et al., 2016). In addition, the amount and/or type of neurotrophic factors could also affect the appearance of ALS-related phenotypes, as some neurotrophic factors could affect ALS (Henriques et al., 2010). This should also be taken into account. As indicated previously, checking specific motor neuron markers (Islet $1, \mathrm{Hb} 9, . .$.$) in combination$ with functional analysis is crucial to identify motor neurons in culture (Davis-Dusenbery et al., 2014; Sances et al., 2016).

By definition, both upper and lower motor neurons are affected in ALS patients (Nijssen et al., 2017). Although most of the protocols are focused on making spinal cord motor neuron with a high efficiency, only one study optimized a protocol to induce around 52\% of upper motor neurons, characterized by PHOX2B and TBX20 upregulation (Maury et al., 2014). This was achieved by using lower concentrations of RA and Wnt agonist (Maury et al., 2014). This opens new perspectives as it gives the opportunity to study different motor neuron types, which could also help to gain more insights into ALS.

Another important drawback of iPSC modeling is that the motor neurons are not in their natural environment. Even cocultures of neurons with other cell types will never be able to model the complexity of the in vivo environment. One possible solution could be to inject iPSCs into the central nervous system in animal models to study their integration, survival, and behavior in the in vivo enviroment.

\section{Reliability of Cortical Neuron Cultures}

During development, mammalian cortical neurons start specialization in the rostral dorsal part of the neural tube (Pierani and Wassef, 2009; O'Leary et al., 2013). The neuroepithelial cells near the ventricular zone (VZ) and subventricular zone (SVZ) develop into the pyramidal neurons, interneurons, and glial cells in the cortex (Noctor et al., 2004). The early postmitotic neurons subsequently migrate away to form the cortical plate (CP) and then separate into a marginal zone (MZ, Layer I) and a deep subplate (SP) (Noctor et al., 2004). Cajal-Retzius cell are developed from the layer I (Noctor et al., 2004). Other specific cortical layers (II-VI) are formed from the CP (Noctor et al.,
2004). The SP is formed by migrating through the intermediate zone (IZ), which is a layer that finally contains the axonal tracts of the cortex. At the same time, the SVZ appears between the VZ and the IZ (Noctor et al., 2004; Clinton et al., 2014). The SVZ mainly produces glia (Noctor et al., 2004; Clinton et al., 2014). The glia function as scaffolds to support and direct the migration of new neurons from the VZ to the CP (Noctor et al., 2004; Clinton et al., 2014). Maturing neuronal axons migrate out toward their targets and form functional synapses (Noctor et al., 2004).

The cortical neuron differentiation in vitro seems to be also very complicated. There are two main reasons for this. First, the cortex contains plenty of neuronal subtypes, which work together in a very complex way. Second, the architecture of the different cortical layers is very difficult to achieve in vitro.

In order to address the differentiation in the different cortical subtypes, a protocol was developed without the addition of morphogens (Espuny-Camacho et al., 2013). Only the BMP inhibitor, Noggin, was used to increase the neuronal differentiation from human iPSCs (Espuny-Camacho et al., 2013). Furthermore, pyramidal neurons from different layers were obtained at different time points (Espuny-Camacho et al., 2013). Pax6 and Otx1/2 were expressed after 10-19 days of differentiation, which resembles early dorsal forebrain (EspunyCamacho et al., 2013). The first neurons are positive for TBR1, calretinin, and reelin which are the markers for CajalRetzius neurons (Espuny-Camacho et al., 2013). Around 2428 days, FOXP2 positive and TBR1/CTIP2 positive neurons of layer VI started to appear. At 37 days, CTIP2 positive neurons were present (Espuny-Camacho et al., 2013). From 40 days on, the TBR1-positive neurons were increasing, while calretinin positive neurons decreased (Espuny-Camacho et al., 2013). This resembles the TBR $1+$ /calretinin- deep layer neurons (VI and V) (Espuny-Camacho et al., 2013). At the last time point (61-72 days), STATB2 positive neurons resembling the layer $\mathrm{V}$ and upper layer appeared in culture. In addition, CUX1/BRN2 positive neurons of the upper layer appeared at the end (Espuny-Camacho et al., 2013). At the same time, deep layer markers were downregulated. Electrophysiological properties were confirmed by patch clamp experiments. After transplantation into mouse brain, the in vitro derived cortical neurons could integrate properly and formed axonal projections and dendritic patterns (Espuny-Camacho et al., 2013). Another study reported the differentiation of cortical neurons by using different morphogens in a $2 \mathrm{D}$ system (Shi et al., 2012). In this $2 \mathrm{D}$ model, neuronal subtypes that belong to different cortical layers appeared at staggered time points, much like during development, and integrated amongst each other.

Another major challenge is to mimic the complex structure of the cortex in vitro. Some initial spatial patterns are observed in $2 \mathrm{D}$ culture. For instance, neuronal progenitors form rosettes which have typical apicobasal polarity and interkinetic nuclear migration (Espuny-Camacho et al., 2013). These features are typical in the VZ during cortical development (Eom et al., 2013). However, long term 3D cultures of hESC/iPSC derived neocortex could solve, at least partially, the problem of the complex cortical 
organization (Lancaster and Knoblich, 2014; Zhang Z.-N. et al., 2016). These 3D cultures started from hESC/iPSC (Lancaster and Knoblich, 2014). Wnt inhibitor and TGF $\beta$ inhibitor combined with low cell adhesion culture plate were used to trigger cortical generation during day 0 to day 18 (Lancaster and Knoblich, 2014). From day 18 onwards, further long term cortical neuroepithelial cultures were started by controlling the environment (proper substrate and $40 \% \mathrm{O}_{2} / 5 \% \mathrm{CO}_{2}$; Lancaster and Knoblich, 2014). These cortical neuroepithelial cells could be kept in culture for more than 13 weeks and formed multilayer structures including three neuronal zones (SP, CP, and CajalRetzius cell zones) and three progenitor zones (VZ, SVZ, and IZ), which were similarly organized as in the human fetal cortex (Lancaster and Knoblich, 2014). Although it is a complicated protocol, this breakthrough will certainly contribute to a better modeling of FTD in vitro and has the potential to be used for future drug testing.

\section{Relevance of Phenotypes to ALS/FTD Aging}

Both ALS and FTD are age-related neurodegenerative diseases with symptoms occurring late in life. As a consequence, the question arises whether relevant phenotypes can be observed in cultured motor neurons that can be kept in culture for several weeks or at most a few months. When ALS/FTD patient are sick, their neurons have already suffered the consequence of the disease process for many years. In contrast, the iPSC-derived neurons are much younger and could more closely resemble the fetal stages, rather than an adult stage. In the best case, these young neurons could mimic the presymptomatic phase of ALS/FTD (Inoue, 2010). Despite the fact that proteomic data indicate that there are clear resemblances between motor neurons derived from endogenous spinal motor neurons (Toma et al., 2015), it is reasonable to expect that aging could play a crucial role in the development of the disease-related phenotypes. To properly mimic late stages of ALS/FTD in vitro, inducing aging and setting landmarks of aging could be necessary. Nine features of mammalian aging are proposed as typical hallmarks, including genomic instability, telomere attrition, epigenetic alterations, loss of proteostasis, deregulated nutrient sensing, mitochondrial dysfunction, cellular senescence, stem cell exhaustion, and altered intercellular communication (López-Otín et al., 2013). One approach of inducing aging in iPSC-derived neurons is to use progerin (Miller et al., 2013). Progerin is an aberrant form of the nuclear architectural protein lamin $\mathrm{A}$ and can cause the premature aging disease Hutchinson-Gilford Progeria via inducing DNA damage (Musich and Zou, 2011; Miller et al., 2013). It is also observed in physiological aging. By treating neurons with progerin for a few days, multiple aging-related characteristics were observed including genomic instability, telomere attrition, and reactive oxygen species (Miller et al., 2013). Although this study only tested this approach in dopaminergic neurons, it is worth attempting this strategy in other neuronal types.

Another recent approach is to directly convert fibroblasts into neurons by transfecting transcription factors with a cocktail of small molecules (Hu et al., 2015; Liu et al., 2016). These directly induced neurons, also called iNeurons, show an agespecific transcriptional background and an age-related reduction of the nuclear transporter RanBP17 (Mertens et al., 2015; Gopalakrishnan et al., 2017). These iNeurons could present with more relevant phenotypes as these induced neurons did not undergo a complete reprogramming which might repair the macromolecular damage which could contribute to ALS/FTD related phenotypes (Mertens et al., 2015; Gopalakrishnan et al., 2017). One disadvantage of these iNeurons is that the fibroblasts used as starting material are not an unlimited resource of cells.

\section{Environmental Factors}

Apart from aging, environmental factors could contribute to ALS/FTD, although convincing evidence for this is still scarce (Ingre et al., 2015). These environmental factors could eventually include malnutrition, hypoxia and psychological stress (Ingre et al., 2015). All these factors could lead to oxidative stress. Clinically, oxidative stress biomarkers in cerebrospinal fluid, plasma, and urine are elevated in ALS/FTD patients, suggesting that oxidative stress could play a pivotal role in motor neuron or cortical neuron degeneration (D'Amico et al., 2013; Mao, 2013; Turner et al., 2013). Moreover, the recently approved drug, edaravone, is thought to exert its therapeutic effect by counteracting oxidative stress (Hardiman and van den Berg, 2017). In addition, oxidative stress is also a major event during aging (López-Otín et al., 2013). Induction of oxidative stress in vitro could be helpful to model ALS/FTD associated phenotypes. Arsenite treatment and hydrogen peroxide are two examples to induce stress (Henkler et al., 2010). Stress granules and FUS/TDP-43 protein aggregations were reported to appear after adding oxidative stress (Dewey et al., 2012; Carrì et al., 2015; Lenzi et al., 2015). In addition, shortage of certain growth factors in ALS (e.g., VEGF, BDNF, GDNF, CNTF, ...) were observed and could contribute to ALS disease progression in vivo (Bogaert et al., 2010; Henriques et al., 2010). Therefore, removal of growth factors can serve as a strategy to induce phenotypes in in vivo models. Moreover, based on the discovery of physiological changes in ALS iPSC models (Wainger et al., 2014; Devlin et al., 2015; Naujock et al., 2016), addition of excitotoxins could also be a method to induce phenotypes.

\section{CONCLUSIONS}

In this review, we systematically summarized the published iPSC models of ALS/FTD, along with their advancements in our knowledge of these complex diseases, but as well as their current drawbacks and discrepancies. Indeed, there are many advantages to modeling ALS/FTD using iPSCs, however, one always has to keep in mind that this is just another model for ALS/FTD. It remains an in vitro model with all the disadvantages that come with it. Neuronal cultures could provide results that might not be relevant to the in vivo disease process. As a consequence, translating results from iPSC-related in vitro work into clinical trials without prior confirmation in additional models or validation in patient material should be avoided. 


\section{AUTHOR CONTRIBUTIONS}

WG contributed to the writing and organization of the whole manuscript. LF contributed to the C9ORF72 part and the figures of this review. RP contributed to the general improvement of the manuscript. LVDB contributed to the organization and quality control of this manuscript.

\section{ACKNOWLEDGMENTS}

Research of the authors is supported by KU Leuven (C1 and "Opening the Future" Fund), VIB, the "Fund for

\section{REFERENCES}

Alexianu, M. E., Kozovska, M., and Appel, S. H. (2001). Immune reactivity in a mouse model of familial ALS correlates with disease progression. Neurology 57, 1282-1289. doi: 10.1212/WNL.57.7.1282

Almeida, S., Gascon, E., Tran, H., Chou, H. J., Gendron, T. F., Degroot, S., et al. (2013). Modeling key pathological features of frontotemporal dementia with C9ORF72 repeat expansion in iPSC-derived human neurons. Acta Neuropathol. 126, 385-399. doi: 10.1007/s00401-013-1149-y

Almeida, S., Zhang, Z., Coppola, G., Mao, W., Futai, K., Karydas, A., et al. (2012). Induced pluripotent stem cell models of progranulin-deficient frontotemporal dementia uncover specific reversible neuronal defects. Cell Rep. 2, 789-798. doi: 10.1016/j.celrep.2012.09.007

Alves, C. J., Dariolli, R., Jorge, F. M., Monteiro, M. R., Maximino, J. R., Martins, R. S., et al. (2015). Gene expression profiling for human iPS-derived motor neurons from sporadic ALS patients reveals a strong association between mitochondrial functions and neurodegeneration. Front. Cell Neurosci. 9:289. doi: 10.3389/fncel.2015.00289

Amoroso, M. W., Croft, G. F., Williams, D. J., O’Keeffe, S., Carrasco, M. A., Davis, A. R., et al. (2013). Accelerated high-yield generation of limbinnervating motor neurons from human stem cells. J. Neurosci. 33, 574-586. doi: 10.1523/JNEUROSCI.0906-12.2013

Baker, M. (2012). Reprogramming: faithful reporters. Nat. Methods 9, 231-234. doi: $10.1038 /$ nmeth.1899

Bang, J., Spina, S., and Miller, B. L. (2015). Frontotemporal dementia. Lancet 386, 1672-1682. doi: 10.1016/S0140-6736(15)00461-4

Barber, S. C., Mead, R. J., and Shaw, P. J. (2006). Oxidative stress in ALS: a mechanism of neurodegeneration and a therapeutic target. Biochim. Biophys. Acta Mol. Basis Dis. 1762, 1051-1067. doi: 10.1016/j.bbadis.2006.03.008

Beurdeley, M., Bietz, F., Li, J., Thomas, S., Stoddard, T., Juillerat, A., et al. (2013). Compact designer TALENs for efficient genome engineering. Nat. Commun. 4:1762. doi: $10.1038 /$ ncomms 2782

Bhandari, V., and Bateman, A. (1992). Structure and chromosomal location of the human granulin gene. Biochem. Biophys. Res. Commun. 188, 57-63. doi: 10.1016/0006-291X(92)92349-3

Bilican, B., Serio, A., Barmada, S. J., Nishimura, A. L., Sullivan, G. J., Carrasco, M., et al. (2012). Mutant induced pluripotent stem cell lines recapitulate aspects of TDP-43 proteinopathies and reveal cell-specific vulnerability. Proc. Natl. Acad. Sci. U.S.A. 109, 5803-5808. doi: 10.1073/pnas.1202922109

Boeynaems, S., Bogaert, E., Van Damme, P., and Van Den Bosch, L. (2016). Inside out: the role of nucleocytoplasmic transport in ALS and FTLD. Acta Neuropathol. 132, 159-173. doi: 10.1007/s00401-016-1586-5

Bogaert, E., Van Damme, P., Poesen, K., Dhondt, J., Hersmus, N., Kiraly, D., et al. (2010). VEGF protects motor neurons against excitotoxicity by upregulation of GluR2. Neurobiol. Aging 31, 2185-2191. doi: 10.1016/j.neurobiolaging.2008.12.007

Boxer, A. L., and Miller, B. L. (2005). Clinical features of frontotemporal dementia. Alzheimer Dis. Assoc. Disord. 19, S3-S6. doi: 10.1097/01.wad.0000183086.99691.91

Brun, A., Englund, B., Gustafon, L., Passant, U., Mann, D. M., and Snowden, J. S. (1994). Clinical and neuropathological criteria for frontotemporal dementia.
Scientific Research Flanders" (FWO-Vlaanderen), the Agency for Innovation by Science and Technology (IWT; SBO-iPSCAF), the Belgian Government (Interuniversity Attraction Poles Programme P7/16 initiated by the Belgian Federal Science Policy Office), the Thierry Latran Foundation, the "Association Belge contre les Maladies neuro-Musculaires" (ABMM) and the ALS Liga België ("A Cure for ALS"). WG is supported by the China Scholarship Council (CSC). RP was supported by grants from the Central Remedial Clinic (CRC) Ireland and the National University of Ireland (NUI) and is currently supported by the FWO-Vlaanderen.
The lund and manchester groups. J. Neurol. Neurosurg. Psychiatry 57, 416-418. doi: 10.1136/jnnp.57.4.416

Buganim, Y., Markoulaki, S., Van Wietmarschen, N., Hoke, H., Wu, T., Ganz, K., et al. (2014). The developmental potential of iPSCs is greatly influenced by reprogramming factor selection. Cell Stem Cell. 15, 295-309. doi: 10.1016/j.stem.2014.07.003

Burkhardt, M. F., Martinez, F. J., Wright, S., Ramos, C., Volfson, D., Mason, M., et al. (2013). A cellular model for sporadic ALS using patientderived induced pluripotent stem cells. Mol. Cell. Neurosci. 56, 355-364. doi: 10.1016/j.mcn.2013.07.007

Burrell, J. R., Halliday, G. M., Kril, J. J., Ittner, L. M., Götz, J., Kiernan, M. C., et al. (2016). The frontotemporal dementia-motor neuron disease continuum. Lancet 388, 919-931. doi: 10.1016/S0140-6736(16)00737-6

Carrì, M. T., Valle, C., Bozzo, F., and Cozzolino, M. (2015). Oxidative stress and mitochondrial damage: importance in non-SOD1 ALS. Front. Cell Neurosci. 9:41. doi: 10.3389/fncel.2015.00041

Carroll, D. (2011). Genome engineering with zinc-finger nucleases. Genetics 188, 773-782. doi: 10.1534/genetics.111.131433

Chen, H., Qian, K., Du, Z., Cao, J., Petersen, A., Liu, H., et al. (2014). Modeling ALS with iPSCs reveals that mutant SOD1 misregulates neurofilament balance in motor neurons. Cell Stem Cell. 14, 796-809. doi: 10.1016/j.stem.2014.02.004

Cho, S. W., Kim, S., Kim, Y., Kweon, J., Kim, H. S., Bae, S., et al. (2014). Analysis of off-target effects of CRISPR/Cas-derived RNA-guided endonucleases and nickases. Genome Res. 24, 132-141. doi: 10.1101/gr.162339.113

Clinton, B. K., Cunningham, C. L., Kriegstein, A. R., Noctor, S. C., and MartinezCerdeño, V. (2014). Radial glia in the proliferative ventricular zone of the embryonic and adult turtle, Trachemys scripta elegans. Neurogenesis 1, 1-13. doi: 10.4161/23262125.2014.970905

Cooper-Knock, J., Kirby, J., Highley, R., and Shaw, P. J. (2015). The spectrum of C9ORF72-mediated neurodegeneration and amyotrophic lateral sclerosis. Neurotherapeutics 12, 326-339. doi: 10.1007/s13311-015-0342-1

D’Amico, E., Factor-Litvak, P., Santella, R. M., and Mitsumoto, H. (2013). Clinical perspective on oxidative stress in sporadic amyotrophic lateral sclerosis. Free Radic. Biol. Med. 65, 509-527. doi: 10.1016/j.freeradbiomed.2013. 06.029

Dafinca, R., Scaber, J., Ababneh, N., Lalic, T., Weir, G., Christian, H., et al. (2016). C9ORF72 hexanucleotide expansions are associated with altered ER calcium homeostasis and stress granule formation in iPSC-derived neurons from patients with amyotrophic lateral sclerosis and frontotemporal dementia. Stem Cells 34, 2063-2078. doi: 10.1002/stem.2388

Dandulakis, M. G., Meganathan, K., Kroll, K. L., Bonni, A., and Constantino, J. N. (2016). Complexities of $\mathrm{X}$ chromosome inactivation status in female human induced pluripotent stem cells a brief review and scientific update for autism research. J. Neurodev. Disord. 8:22. doi: 10.1186/s11689-016-9155-8

Davis-Dusenbery, B. N., Williams, L. A., Klim, J. R., and Eggan, K. (2014). How to make spinal motor neurons. Development 141, 491-501. doi: 10.1242/dev.097410

Decker, J. M., Krüger, L., Sydow, A., Dennissen, F. J., Siskova, Z., Mandelkow, E., et al. (2016). The Tau/A152T mutation, a risk factor for frontotemporalspectrum disorders, leads to NR2B receptor-mediated excitotoxicity. EMBO Rep. 17, 552-569. doi: 10.15252/embr.201541439 
DeJesus-Hernandez, M., Mackenzie, I. R., Boeve, B. F., Boxer, A. L., Baker, M., Rutherford, N. J., et al. (2011). Expanded GGGGCC hexanucleotide repeat in noncoding region of C9ORF72 causes chromosome 9p-Linked, FTD and ALS. Neuron 72, 245-256. doi: 10.1016/j.neuron.2011.09.011

Devlin, A.-C., Burr, K., Borooah, S., Foster, J. D., Cleary, E. M., Geti, I., et al. (2015). Human iPSC-derived motoneurons harbouring TARDBP or C9ORF72 ALS mutations are dysfunctional despite maintaining viability. Nat. Commun. 6:5999. doi: 10.1038/ncomms6999

De Vos, K. J., and Hafezparast, M. (2017). Neurobiology of axonal transport defects in motor neuron diseases: opportunities for translational research? Neurobiol. Dis. 105, 283-299. doi: 10.1016/j.nbd.2017.02.004

Dewey, C. M., Cenik, B., Sephton, C. F., Johnson, B. A., Herz, J., and Yu, G. (2012). TDP-43 aggregation in neurodegeneration: are stress granules the key? Brain Res. 1462, 16-25. doi: 10.1016/j.brainres.2012.02.032

Dimos, J. T., Rodolfa, K. T., Niakan, K. K., Weisenthal, L. M., Mitsumoto, H., Chung, W., et al. (2008). Induced pluripotent stem cells generated from patients with ALS can be differentiated into motor neurons. Science 321, 1218-1221. doi: 10.1126/science.1158799

Donnelly, C. J., Zhang, P. W., Pham, J. T., Haeusler, A. R., Mistry, N. A., Vidensky, S., et al. (2013). RNA toxicity from the ALS/FTD C9ORF72 expansion is mitigated by antisense intervention. Neuron 80, 415-428. doi: 10.1016/j.neuron.2013.10.015

Douvaras, P., Rusielewicz, T., Kim, K. H., Haines, J. D., Casaccia, P., and Fossati, V. (2016). Epigenetic modulation of human induced pluripotent stem cell differentiation to oligodendrocytes. Int. J. Mol. Sci. 17:614. doi: 10.3390/ijms17040614

Du, Z.-W., Chen, H., Liu, H., Lu, J., Qian, K., Huang, C. L., et al. (2015). Generation and expansion of highly pure motor neuron progenitors from human pluripotent stem cells. Nat. Commun. 6:6626. doi: 10.1038/ncomms7626

Egawa, N., Kitaoka, S., Tsukita, K., Naitoh, M., Takahashi, K., Yamamoto, T., et al. (2012). Drug screening for ALS using patient-specific induced pluripotent stem cells. Sci. Transl. Med. 4:145ra104. doi: 10.1126/scitranslmed.3004052

Emdad, L., D'Souza, S. L., Kothari, H. P., Qadeer, Z. A., and Germano, I. M. (2012). Efficient differentiation of human embryonic and induced pluripotent stem cells into functional astrocytes. Stem Cells Dev. 21, 404-410. doi: $10.1089 /$ scd. 2010.0560

Engelhardt, J. I., Tajti, J., and Appel, S. H. (1993). Lymphocytic infiltrates in the spinal cord in amyotrophic lateral sclerosis. Arch. Neurol. 50, 30-36. doi: 10.1001/archneur.1993.00540010026013

Eom, D. S., Amarnath, S., and Agarwala, S. (2013). Apicobasal polarity and neural tube closure. Dev. Growth Differ. 55, 164-172. doi: 10.1111/dgd.12030

Espuny-Camacho, I., Michelsen, K. A., Gall, D., Linaro, D., Hasche, A., Bonnefont, J., et al. (2013). Pyramidal neurons derived from human pluripotent stem cells integrate efficiently into mouse brain circuits in vivo. Neuron 77, 440-456. doi: 10.1016/j.neuron.2012.12.011

Farg, M. A., Sundaramoorthy, V., Sultana, J. M., Yang, S., Atkinson, R. A., Levina, V., et al. (2014). C9ORF72, implicated in amyotrophic lateral sclerosis and frontotemporal dementia, regulates endosomal trafficking. Hum. Mol. Genet. 23, 3579-3595. doi: 10.1093/hmg/ddu068

Ferraiuolo, L., Meyer, K., Sherwood, T. W., Vick, J., Likhite, S., Frakes, A., et al. (2016). Oligodendrocytes contribute to motor neuron death in ALS via SOD1-dependent mechanism. Proc. Natl. Acad. Sci. U.S.A. 113, E6496-E6505. doi: $10.1073 /$ pnas.1607496113

Ferrari, R., Kapogiannis, D. D., Huey, E., and Momeni, P. (2011). FTD and ALS: a tale of two diseases. Curr. Alzheimer Res. 8, 273-294. doi: $10.2174 / 156720511795563700$

Fong, H., Wang, C., Knoferle, J., Walker, D., Balestra, M. E., Tong, L. M., et al. (2013). Genetic correction of tauopathy phenotypes in neurons derived from human induced pluripotent stem cells. Stem Cell Rep. 1, 226-234. doi: 10.1016/j.stemcr.2013.08.001

Fong, J. C., Karydas, A. M., and Goldman, J. S. (2012). Genetic counseling for FTD/ALS caused by the C9ORF72 hexanucleotide expansion. Alzheimers Res. Ther. 4:27. doi: 10.1186/alzrt130

Freibaum, B. D., Lu, Y., Lopez-Gonzalez, R., Kim, N. C., Almeida, S., Lee, K. H., et al. (2015). GGGGCC repeat expansion in C9ORF72 compromises nucleocytoplasmic transport. Nature 525, 129-133. doi: 10.1038/nature14974

Fritz, E., Izaurieta, P., Weiss, A., Mir, F. R., Rojas, P., Gonzalez, D., et al. (2013). Mutant SOD1-expressing astrocytes release toxic factors that trigger motoneuron death by inducing hyperexcitability. J. Neurophysiol. 109, 2803-2814. doi: 10.1152/jn.00500.2012

Geevasinga, N., Menon, P., Howells, J., Nicholson, G. A., Kiernan, M. C., and Vucic, S. (2015). Axonal ion channel dysfunction in C9ORF72 familial amyotrophic lateral sclerosis. JAMA Neurol. 72, 49-57. doi: 10.1001/jamaneurol.2014.2940

Gendron, T. F., Bieniek, K. F., Zhang, Y. J., Jansen-West, K., Ash, P. E., Caulfield, T., et al. (2013). Antisense transcripts of the expanded C9ORF72 hexanucleotide repeat form nuclear RNA foci and undergo repeat-associated non-ATG translation in c9FTD/ALS. Acta Neuropathol. 126, 829-844. doi: 10.1007/s00401-013-1192-8

Gopalakrishnan, S., Hor, P., and Ichida, J. K. (2017). New approaches for direct conversion of patient fibroblasts into neural cells. Brain Res. 1656, 2-13. doi: 10.1016/j.brainres.2015.10.012

Gouti, M., Tsakiridis, A., Wymeersch, F. J., Huang, Y., Kleinjung, J., Wilson, V., et al. (2014). In vitro generation of neuromesodermal progenitors reveals distinct roles for wnt signalling in the specification of spinal cord and paraxial mesoderm identity. PLoS Biol. 12:e1001937. doi: 10.1371/journal.pbio. 1001937

Guo, W., Naujock, M., Fumagalli, L., Vandoorne, T., Baatsen, P., Boon, R., et al. (2017). HDAC6 inhibition reverses axonal transport defects in motor neurons derived from FUS-ALS patients. Nat. Commun. 8:861. doi: 10.1038/s41467-017-00911-y

Guven, G., Lohmann, E., Bras, J., Gibbs, J. R., Gurvit, H., Bilgic, B., et al. (2016). Mutation frequency of the major frontotemporal dementia genes, MAPT, GRN and C9ORF72 in a Turkish cohort of dementia patients. PLoS ONE 11:e0162592. doi: 10.1371/journal.pone.0162592

Hall, E. D., Oostveen, J. A., and Gurney, M. E., (1998). Relationship of microglial and astrocytic activation to disease onset and progression in a transgenic model of familial ALS. Glia 23, 249-256.

Hara, T., Nakamura, K., Matsui, M., Yamamoto, A., Nakahara, Y., SuzukiMigishima, R., et al. (2006). Suppression of basal autophagy in neural cells causes neurodegenerative disease in mice. Nature 441, 885-889. doi: $10.1038 /$ nature 04724

Hardiman, O., and van den Berg, L. H. (2017). Edaravone: a new treatment for ALS on the horizon? Lancet Neurol. 16, 490-491. doi: 10.1016/S1474-4422(17)30163-1

He, J., Mangelsdorf, M., Fan, D., Bartlett, P., and Brown, M. A. (2015). Amyotrophic lateral sclerosis genetic studies: from genome-wide association mapping to genome sequencing. Neuroscientist 21, 599-615. doi: $10.1177 / 1073858414555404$

Hedlund, E., and Isacson, O. (2008). ALS model glia can mediate toxicity to motor neurons derived from human embryonic stem cells. Cell Stem Cell. 3, 575-576. doi: 10.1016/j.stem.2008.11.004

Henkler, F., Brinkmann, J., and Luch, A. (2010). The role of oxidative stress in carcinogenesis induced by metals and xenobiotics. Cancers 2, 376-396. doi: 10.3390/cancers2020376

Henriques, A., Pitzer, C., and Schneider, A. (2010). Neurotrophic growth factors for the treatment of amyotrophic lateral sclerosis: where do we stand? Front. Neurosci. 4:32. doi: 10.3389/fnins.2010.00032

Henry, K. A., Fagliano, J., Jordan, H. M., Rechtman, L., and Kaye, W. E. (2015). Geographic variation of amyotrophic lateral sclerosis incidence in New Jersey, 2009-2011. Am. J. Epidemiol. 182, 512-519. doi: 10.1093/aje/kwv095

Higelin, J., Demestre, M., Putz, S., Delling, J. P., Jacob, C., Lutz, A. K., et al. (2016). FUS mislocalization and vulnerability to DNA damage in ALS patients derived hiPSCs and aging motoneurons. Front. Cell. Neurosci. 10:290. doi: $10.3389 /$ fncel.2016.00290

Higgins, C. M. J., Jung, C., and Xu, Z. (2003). ALS-associated mutant SOD1G93A causes mitochondrial vacuolation by expansion of the intermembrane space and by involvement of SOD1 aggregation and peroxisomes. BMC Neurosci. 4:16. doi: $10.1186 / 1471-2202-4-16$

Hu, B.-Y., Du, Z.-W., Li, X.-J., Ayala, M., and Zhang, S.-C. (2009). Human oligodendrocytes from embryonic stem cells: conserved $\mathrm{SHH}$ signaling networks and divergent FGF effects. Development 136, 1443-1452. doi: 10.1242/dev.029447

Hu, B.-Y., and Zhang, S.-C. (2009). Differentiation of spinal motor neurons from pluripotent human stem cells. Nat. Protoc. 4, 1295-1304. doi: $10.1038 /$ nprot.2009.127 
Hu, W., Qiu, B., Guan, W., Wang, Q., Wang, M., Li, W., et al. (2015). Direct conversion of normal and Alzheimer's disease human fibroblasts into neuronal cells by small molecules. Cell Stem Cell. 17, 204-212. doi: 10.1016/j.stem.2015.07.006

Ichiyanagi, N., Fujimori, K., Yano, M., Ishihara-Fujisaki, C., Sone, T., Akiyama, T., et al. (2016). Establishment of in Vitro FUS-associated familial amyotrophic lateral sclerosis model using human induced pluripotent stem cells. Stem Cell Rep. 6, 496-510. doi: 10.1016/j.stemcr.2016. 02.011

Ingre, C., Roos, P. M., Piehl, F., Kamel, F., and Fang, F. (2015). Risk factors for amyotrophic lateral sclerosis. Clin. Epidemiol. 7, 181-193. doi: 10.2147/CLEP.S37505

Inoue, H. (2010). Between disease and a dish. Exp. Cell Res. 316, 2560-2564. doi: 10.1016/j.yexcr.2010.04.022

Karageorgiou, E., and Miller, B. L. (2014). Frontotemporal lobar degeneration: a clinical approach. Semin. Neurol. 34, 189-201. doi: 10.1055/s-0034-1381735

Karow, M., Chavez, C. L., Farruggio, A. P., Geisinger, J. M., Keravala, A., Jung, W. E., et al. (2011). Site-specific recombinase strategy to create induced pluripotent stem cells efficiently with plasmid DNA. Stem Cells 29, 1696-1704. doi: 10.1002/stem.730

Kaus, A., and Sareen, D. (2015). ALS patient stem cells for unveiling disease signatures of motoneuron susceptibility: perspectives on the deadly mitochondria, ER stress and calcium triad. Front. Cell. Neurosci. 9:448. doi: 10.3389/fncel.2015.00448

Kawamata, H., and Manfredi, G. (2010). Mitochondrial dysfunction and intracellular calcium dysregulation in ALS. Mech. Ageing Dev. 131, 517-526. doi: 10.1016/j.mad.2010.05.003

Kiecker, C., Bates, T., and Bell, E. (2016). Molecular specification of germ layers in vertebrate embryos. Cell. Mol. Life Sci. 73, 923-947. doi: 10.1007/s00018-015-2092-y

Kiskinis, E., Sandoe, J., Williams, L. A., Boulting, G. L., Moccia, R., Wainger, B. J., et al. (2014). Pathways disrupted in human ALS motor neurons identified through genetic correction of mutant SOD1. Cell Stem Cell. 14, 781-795. doi: 10.1016/j.stem.2014.03.004

Komatsu, M., Waguri, S., Chiba, T., Murata, S., Iwata, J., Tanida, I., et al. (2006). Loss of autophagy in the central nervous system causes neurodegeneration in mice. Nature 441, 880-884. doi: 10.1038/nature04723

Kong, J., and Xu, Z. (1998). Massive mitochondrial degeneration in motor neurons triggers the onset of amyotrophic lateral sclerosis in mice expressing a mutant SOD1. J. Neurosci. 18, 3241-3250.

Lagier-Tourenne, C., Polymenidou, M., and Cleveland, D. W. (2010). TDP-43 and FUS/TLS: emerging roles in RNA processing and neurodegeneration. Hum. Mol. Genet. 19, R46-R64. doi: 10.1093/hmg/ddq137

Lancaster, M. A., and Knoblich, J. A. (2014). Generation of cerebral organoids from human pluripotent stem cells. Nat. Protoc. 9, 2329-2340. doi: 10.1038/nprot.2014.158

Lashley, T., Rohrer, J. D., Mead, S., and Revesz, T. (2015). Review: an update on clinical, genetic and pathological aspects of frontotemporal lobar degenerations. Neuropathol. Appl. Neurobiol. 41, 858-881. doi: $10.1111 /$ nan. 12250

Lee, H. J., Kim, K. S., Ahn, J., Bae, H. M., Lim, I., and Kim, S. U. (2014). Human motor neurons generated from neural stem cells delay clinical onset and prolong life in ALS mouse model. PLoS ONE 9:e97518. doi: 10.1371/journal.pone.0097518

Lee, H., Shamy, G. A., Elkabetz, Y., Schofield, C. M., Harrsion, N. L., Panagiotakos, G., et al. (2007). Directed differentiation and transplantation of human embryonic stem cell-derived motoneurons. Stem Cells 25, 1931-1939. doi: 10.1634/stemcells.2007-0097

Lee, S., and Huang, E. J. (2017). Modeling, ALS and FTD with iPSC-derived neurons. Brain Res. 1656, 88-97. doi: 10.1016/j.brainres.2015.10.003

Lenzi, J., De Santis, R., de Turris, V., Morlando, M., Laneve, P., Calvo, A., et al. (2015). ALS mutant FUS proteins are recruited into stress granules in induced pluripotent stem cell-derived motoneurons. Dis. Model. Mech. 8, 755-766. doi: 10.1242/dmm.020099

Levine, T. P., Daniels, R. D., Gatta, A. T., Wong, L. H., and Hayes, M. J. (2013). The product of C9ORF72, a gene strongly implicated in neurodegeneration, is structurally related to DENN Rab-GEFs. Bioinformatics 29, 499-503. doi: 10.1093/bioinformatics/bts725
Li, X.-J., Hu, B.-Y., Jones, S. A., Zhang, Y. S., Lavaute, T., Du, Z. W., et al. (2008). Directed differentiation of ventral spinal progenitors and motor neurons from human embryonic stem cells by small molecules. Stem Cells 26, 886-893. doi: 10.1634/stemcells.2007-0620

Li, Y., Cao, J., Chen, M., Li, J., Sun, Y., Zhang, Y., et al. (2017). Abnormal neural progenitor cells differentiated from induced pluripotent stem cells partially mimicked development of TSC2 neurological abnormalities. Stem Cell Rep. 8, 883-893. doi: 10.1016/j.stemcr.2017.02.020

Ling, S.-C., Polymenidou, M., and Cleveland, D. W. (2013). Converging mechanisms in ALS and FTD: disrupted RNA and protein homeostasis. Neuron. 79, 416-438. doi: 10.1016/j.neuron.2013.07.033

Liu, M. L., Zang, T., and Zhang, C. L. (2016). Direct lineage reprogramming reveals disease-specific phenotypes of motor neurons from human ALS patients. Cell Rep. 14, 115-128. doi: 10.1016/j.celrep.2015.12.018

Liu, X., Chen, J., Liu, W., Li, X., Chen, Q., Liu, T., et al. (2015). The fused in sarcoma protein forms cytoplasmic aggregates in motor neurons derived from integration-free induced pluripotent stem cells generated from a patient with familial amyotrophic lateral sclerosis carrying the FUS-P525L mutation. Neurogenetics 16, 223-231. doi: 10.1007/s10048-015-0448-y

Lopez-Gonzalez, R., Lu, Y., Gendron, T. F., Karydas, A., Tran, H., Yang, D., et al. (2016). Poly(GR) in C9ORF72-Related ALS/FTD compromises mitochondrial function and increases oxidative stress and DNA Damage in iPSC-derived motor neurons. Neuron 92, 383-391. doi: 10.1016/j.neuron.2016.09.015

López-Otín, C., Blasco, M. A., Partridge, L., Serrano, M., and Kroemer, G. (2013). The hallmarks of aging. Cell 153, 1194-1217. doi: 10.1016/j.cell.2013.05.039

Mackenzie, I. R. A., Frick, P., and Neumann, M. (2014). The neuropathology associated with repeat expansions in the C9ORF72 gene. Acta Neuropathol. 127, 347-357. doi: 10.1007/s00401-013-1232-4

Madill, M., McDonagh, K., Ma, J., Vajda, A., McLoughlin, P., O’Brien, T., et al. (2017). Amyotrophic lateral sclerosis patient iPSC-derived astrocytes impair autophagy via non-cell autonomous mechanisms. Mol. Brain 10:22. doi: 10.1186/s13041-017-0300-4

Mao, P. (2013). Oxidative stress and its clinical applications in dementia. I. Neurodegener. Dis. 2013:319898. doi: 10.1155/2013/319898.

Masahira, N., Takebayashi, H., Ono, K., Watanabe, K., Ding, L., Furusho, M., et al. (2006). Olig2-positive progenitors in the embryonic spinal cord give rise not only to motoneurons and oligodendrocytes, but also to a subset of astrocytes and ependymal cells. Dev. Biol. 293, 358-369. doi: 10.1016/j.ydbio.2006.02.029

Mattson, M. P., and Magnus, T. (2006). Ageing and neuronal vulnerability. Nat. Rev. Neurosci. 7, 278-294. doi: 10.1038/nrn1886

Maury, Y., Côme, J., Piskorowski, R. A., Salah-Mohellibi, N., Chevaleyre, V., Peschanski, M., et al. (2014). Combinatorial analysis of developmental cues efficiently converts human pluripotent stem cells into multiple neuronal subtypes. Nat. Biotechnol. 33, 89-96. doi: 10.1038/nbt.3049

Mertens, J., Paquola, A. C. M., Ku, M., Hatch, E., Böhnke, L., Ladjevardi, S., et al. (2015). Directly reprogrammed human neurons retain aging-associated transcriptomic signatures and reveal age-related nucleocytoplasmic defects. Cell Stem Cell. 17, 705-718. doi: 10.1016/j.stem.2015.09.001

Meyer, K., Ferraiuolo, L., Miranda, C. J., Likhite, S., McElroy, S., Renusch, S., et al. (2014). Direct conversion of patient fibroblasts demonstrates non-cell autonomous toxicity of astrocytes to motor neurons in familial and sporadic ALS. Proc. Natl. Acad. Sci. U.S.A. 111, 829-832. doi: 10.1073/pnas.1314085111

Miller, J. D., Ganat, Y. M., Kishinevsky, S., Bowman, R. L., Liu, B., Tu, E. Y., et al. (2013). Human iPSC-based modeling of late-onset disease via progerininduced aging. Cell Stem Cell. 13, 691-705. doi: 10.1016/j.stem.2013.11.006

Miller, R. G., Mitchell, J. D., Lyon, M., and Moore, D. H. (2003). Riluzole for amyotrophic lateral sclerosis (ALS)/motor neuron disease (MND). Amyotroph. Lateral Scler. Other Mot. Neuron Disord. 4, 191-206. doi: 10.1002/14651858.CD001447

Mitne-Neto, M., Machado-Costa, M., Marchetto, M. C. N., Bengtson, M. H., Joazeiro, C. A., Tsuda, H., et al. (2011). Downregulation of VAPB expression in motor neurons derived from induced pluripotent stem cells of ALS8 patients. Hum. Mol. Genet. 20, 3642-3652. doi: 10.1093/hmg/ddr284

Musich, P. R., and Zou, Y. (2011). DNA-damage accumulation and replicative arrest in Hutchinson-Gilford progeria syndrome. Biochem. Soc. Trans. 39, 1764-1769. doi: 10.1042/BST20110687

Nagai, M., Re, D. B., Nagata, T., Chalazonitis, A., Jessell, T. M., Wichterle, H., et al. (2007). Astrocytes expressing ALS-linked mutated SOD1 release 
factors selectively toxic to motor neurons. Nat. Neurosci. 10, 615-622. doi: $10.1038 / \mathrm{nn} 1876$

Naujock, M., Stanslowsky, N., Bufler, S., Naumann, M., Reinhardt, P., Sterneckert, J., et al. (2016). 4-Aminopyridine induced activity rescues hypoexcitable motor neurons from amyotrophic lateral sclerosis patient-derived induced. Stem Cells 34, 1563-1575. doi: 10.1002/stem.2354

Nelakanti, R. V., Kooreman, N. G., and Wu, J. C. (2015). Teratoma formation: a tool for monitoring pluripotency in stem cell research. Curr. Protoc. Stem Cell Biol. 2015, 4a.8.1-4a.8.17. doi: 10.1002/9780470151808.sc04a08s32

Neumann, M., Sampathu, D. M., Kwong, L. K., Truax, A. C., Micsenyi, M. C., Chou, T. T., et al. (2006). Ubiquitinated TDP-43 in frontotemporal lobar degeneration and amyotrophic lateral sclerosis. Science 314, 130-133. doi: $10.1126 /$ science. 1134108

Ng, A. S. L., Rademakers, R., and Miller, B. L. (2015). Frontotemporal dementia: a bridge between dementia and neuromuscular disease. Ann. N.Y. Acad. Sci. 1338, 71-93. doi: 10.1111/nyas. 12638

Niedzielska, E., Smaga, I., Gawlik, M., Moniczewski, A., Stankowicz, P., Pera, J., et al. (2016). Oxidative stress in neurodegenerative diseases. Mol. Neurobiol. 53, 4094-4125. doi: 10.1007/s12035-015-9337-5

Nijssen, J., Comley, L. H., and Hedlund, E. (2017). Motor neuron vulnerability and resistance in amyotrophic lateral sclerosis. Acta Neuropathol. 133, 1-23. doi: 10.1007/s00401-017-1708-8

Noctor, S. C., Martinez-Cerdeno, V., Ivic, L., and Kriegstein, A. R. (2004). Cortical neurons arise in symmetric and asymmetric division zones and migrate through specific phases. Nat. Neurosci. 7, 136-144. doi: 10.1038/nn1172

Noto, Y. I., Shibuya, K., Vucic, S., and Kiernan, M. C. (2016). Novel therapies in development that inhibit motor neuron hyperexcitability in amyotrophic lateral sclerosis. Expert Rev. Neurother. 16, 1147-1154. doi: 10.1080/14737175.2016.1197774

O'Leary, D. D. M., Stocker, A. M., and Zembrzycki, A. (2013). “Area patterning of the mammalian cortex," in Comprehensive Developmental Neuroscience: Patterning and Cell Type Specification in the Developing CNS and PNS (Amsterdam: Elsevier Press), 61-85.

Okamoto, K., Hirai, S., Shoji, M., Senoh, Y., and Yamazaki, T. (1990). Axonal swellings in the corticospinal tracts in amyotrophic lateral sclerosis. Acta Neuropathol. 80, 222-226. doi: 10.1007/BF00308929

Onesto, E., Colombrita, C., Gumina, V., Borghi, M. O., Dusi, S., Doretti, A., et al. (2016). Gene-specific mitochondria dysfunctions in human TARDBP and C9ORF72 fibroblasts. Acta Neuropathol. Commun. 4:47. doi: 10.1186/s40478-016-0316-5

Patani, R., Hollins, A. J., Wishart, T. M., Puddifoot, C. A., Alvarez, S., de Lera, A. R., et al. (2011). Retinoid-independent motor neurogenesis from human embryonic stem cells reveals a medial columnar ground state. Nat. Commun. 2:214. doi: $10.1038 /$ ncomms 1216

Patel, A., Lee, H. O., Jawerth, L., Maharana, S., Jahnel, M., Hein, M. Y., et al. (2015). A liquid-to-solid phase transition of the ALS protein FUS accelerated by disease mutation. Cell 162, 1066-1077. doi: 10.1016/j.cell.2015.07.047

Petrov, D., Mansfield, C., Moussy, A., and Hermine, O. (2017). ALS clinical trials review: 20 years of failure. Are we any closer to registering a new treatment? Front. Aging Neurosci. 9:68. doi: 10.3389/fnagi.2017.00068

Picher-Martel, V., Valdmanis, P. N., Gould, P. V., Julien, J.-P., and Dupré, N. (2016). From animal models to human disease: a genetic approach for personalized medicine in ALS. Acta Neuropathol. Commun. 4:70. doi: 10.1186/s40478-016-0340-5

Pickford, F., Marcus, J., Camargo, L. M., Xiao, Q., Graham, D., Mo, J. R., et al. (2011). Progranulin is a chemoattractant for microglia and stimulates their endocytic activity. Am. J. Pathol. 178, 284-295. doi: 10.1016/j.ajpath.2010.11.002

Pierani, A., and Wassef, M. (2009). Cerebral cortex development: from progenitors patterning to neocortical size during evolution. Dev. Growth Differ. 51, 325-342. doi: 10.1111/j.1440-169X.2009.01095.x

Qian, K., Huang, H., Peterson, A., Hu, B., Maragakis, N. J., Ming, G.-I., et al. (2017). Sporadic ALS astrocytes induce neuronal degeneration in vivo. Stem Cell Rep. 8, 843-855. doi: 10.1016/j.stemcr.2017.03.003

Qu, Q., Li, D., Louis, K. R., Li, X., Yang, H., Sun, Q., et al. (2014). High-efficiency motor neuron differentiation from human pluripotent stem cells and the function of Islet-1. Nat. Commun. 5:3449. doi: 10.1038/ncomms4449
Rainero, I., Rubino, E., Michelerio, A., D’Agata, F., Gentile, S., and Pinessi, L. (2017). Recent advances in the molecular genetics of frontotemporal lobar degeneration. Funct. Neurol. 32, 7-16. doi: 10.11138/FNeur/2017.32.1.007

Raitano, S., Ordovàs, L., De Muynck, L., Guo, W., Espuny-Camacho, I., Geraerts, M., et al. (2015). Restoration of progranulin expression rescues cortical neuron generation in an induced pluripotent stem cell model of frontotemporal dementia. Stem Cell Rep. 4, 16-24. doi: 10.1016/j.stemcr.2014.12.001

Ran, F. A., Hsu, P. D. P., Wright, J., Agarwala, V., Scott, D., and Zhang, F. (2013). Genome engineering using the CRISPR-Cas9 system. Nat. Protoc. 8, 2281-2308. doi: 10.1038/nprot.2013.143

Régal, L., Vanopdenbosch, L., Tilkin, P., Van Den Bosch, L., Thijs, V. Sciot, R., et al. (2006). The G93C mutation in superoxide dismutase 1: clinicopathologic phenotype and prognosis. Arch. Neurol. 63, 262-267. doi: 10.1001/archneur.63.2.262

Renton, A. E., Chiò, A., and Traynor, B. J. (2014). State of play in amyotrophic lateral sclerosis genetics. Nat. Neurosci. 17, 17-23. doi: 10.1038/nn.3584

Ribes, V., Balaskas, N., Sasai, N., Cruz, C., Dessaud, E., Cayuso, J., et al. (2010). Distinct sonic hedgehog signaling dynamics specify floor plate and ventral neuronal progenitors in the vertebrate neural tube. Genes Dev. 24, 1186-1200. doi: $10.1101 / \operatorname{gad} .559910$

Rovelet-Lecrux, A., Hannequin, D., Guillin, O., Legallic, S., Jurici, S., Wallon, D., et al. (2010). Frontotemporal dementia phenotype associated with MAPT gene duplication. J. Alzheimers Dis. 21, 897-902. doi: 10.3233/JAD-2010-100441

Rowland, L., and Shneider, N. (2001). Amyotrophic Lateral Sclerosis. N. Engl. J. Med. 344, 1688-1700. doi: 10.1056/NEJM200105313442207

Sances, S., Bruijn, L. I., Chandran, S., Eggan, K., Ho, R., Klim, J. R., et al. (2016). Modeling ALS with motor neurons derived from human induced pluripotent stem cells. Nat. Neurosci. 16, 542-553. doi: 10.1038/nn.4273

Sareen, D., O’Rourke, J. G., Meera, P., Muhammad, A. K., Grant, S., Simpkinson, M., et al. (2013). Targeting RNA foci in iPSC-derived motor neurons from ALS patients with a C9ORF72 repeat expansion. Sci. Transl. Med. 5:208ra149. doi: 10.1126/scitranslmed.3007529

Sasaki, S., and Iwata, M. (2007). Mitochondrial alterations in the spinal cord of patients with sporadic amyotrophic lateral sclerosis. J. Neuropathol. Exp. Neurol. 66, 10-16. doi: 10.1097/nen.0b013e31802c396b

Sasaki, S., and Maruyama, S. (1992). Increase in diameter of the axonal initial segment is an early change in amyotrophic lateral sclerosis. J. Neurol. Sci. 110, 114-120. doi: 10.1016/0022-510X(92)90017-F

Sellier, C., Campanari, M.-L., Julie Corbier, C., Gaucherot, A., Kolb-Cheynel, I., Oulad-Abdelghani, M., et al. (2016). Loss of C9ORF72 impairs autophagy and synergizes with polyQ Ataxin-2 to induce motor neuron dysfunction and cell death. EMBO J. 35, 1-22. doi: 10.15252/embj.201593350

Serio, A., Bilican, B., Barmada, S. J., Ando, D. M., Zhao, C., Siller, R., et al. (2013). Astrocyte pathology and the absence of non-cell autonomy in an induced pluripotent stem cell model of TDP-43 proteinopathy. Proc. Natl. Acad. Sci. U.S.A. 110, 4697-4702. doi: 10.1073/pnas.1300398110

Shi, Y., Kirwan, P., and Livesey, F. J. (2012). Directed differentiation of human pluripotent stem cells to cerebral cortex neurons and neural networks. Nat. Protoc. 7, 1836-1846. doi: 10.1038/nprot.2012.116

Shin, S., Dalton, S., and Stice, S. L. (2005). Human motor neuron differentiation from human embryonic stem cells. Stem Cells Dev. 14, 266-269. doi: $10.1089 / \mathrm{scd} .2005 .14 .266$

Sivadasan, R., Hornburg, D., Drepper, C., Frank, N., Jablonka, S., Hansel, A., et al. (2016). C9ORF72 interaction with cofilin modulates actin dynamics in motor neurons. Nat. Neurosci. 19, 1610-1618. doi: 10.1038/nn.4407

Sullivan, P. M., Zhou, X., Robins, A. M., Paushter, D. H., Kim, D., Smolka, M. B., et al. (2016). The ALS/FTLD associated protein C9ORF72 associates with SMCR8 and WDR41 to regulate the autophagy-lysosome pathway. Acta Neuropathol. Commun. 4:51. doi: 10.1186/s40478-016-0324-5

Takahashi, K., Tanabe, K., Ohnuki, M., Narita, M., Ichisaka, T., Tomoda, K., et al. (2007). Induction of pluripotent stem cells from adult human fibroblasts by defined factors. Cell 107, 861-872. doi: 10.1016/j.cell.2007.11.019

Taylor, J. P., Brown, R. H., and Cleveland, D. W. (2016). Decoding ALS: from genes to mechanism. Nature 539, 197-206. doi: 10.1038/nature20413

Tian, C., Liu, Q., Ma, K., Wang, Y., Chen, Q., Ambroz, R., et al. (2013). Characterization of induced neural progenitors from skin fibroblasts by a novel combination of defined factors. Sci. Rep. 3:1345. doi: 10.1038/srep01345 
Toma, J. S., Shettar, B. C., Chipman, P. H., Pinto, D. M., Borowska, J. P., Ichida, J. K., et al. (2015). Motoneurons derived from induced pluripotent stem cells develop mature phenotypes typical of endogenous spinal motoneurons. J. Neurosci. 35, 1291-1306. doi: 10.1523/JNEUROSCI.2126-14.2015

Tomoda, K., Takahashi, K., Leung, K., Okada, A., Narita, M., Yamada, N. A., et al. (2012). Derivation conditions impact $\mathrm{x}$-inactivation status in female human induced pluripotent stem cells. Cell Stem Cell. 11, 91-99. doi: 10.1016/j.stem.2012.05.019

Tradewell, M. L., Yu, Z., Tibshirani, M., Boulanger, M. C., Durham, H. D., and Richard, S. (2012). Arginine methylation by prmtl regulates nuclearcytoplasmic localization and toxicity of FUS/TLS harbouring ALS-linked mutations. Hum. Mol. Genet. 21, 136-149. doi: 10.1093/hmg/ddr448

Trott, J., Tan, E. K., Ong, S., Titmarsh, D. M., Denil, S. L. I. J., Giam, M., et al. (2017). Long-term culture of self-renewing pancreatic progenitors derived from human pluripotent stem cells. Stem Cell Rep. 8, 1675-1688. doi: 10.1016/j.stemcr.2017.05.019

Turner, M. R., Al-Chalabi, A., Chio, A., Hardiman, O., Kiernan, M. C., Rohrer, J. D., et al. (2017). Genetic screening in sporadic ALS and FTD. J. Neurol. Neurosurg. Psychiatry. 88, 1042-1044. doi: 10.1136/jnnp-2017-315995

Turner, M. R., Bowser, R., Bruijn, L., Dupuis, L., Ludolph, A., McGrath, M., et al. (2013). Mechanisms, models and biomarkers in amyotrophic lateral sclerosis. Amyotroph. Lateral Scler. Frontotemporal Degener. 14(Suppl. 1), 19-32. doi: 10.3109/21678421.2013.778554

Unciti-Broceta, J. D., Cano-Cortés, V., Altea-Manzano, P., Pernagallo, S., DíazMochón, J. J., and Sánchez-Martín, R. M. (2015). Number of nanoparticles per cell through a spectrophotometric method - a key parameter to assess nanoparticle-based cellular assays. Sci. Rep. 5:10091. doi: 10.1038/srep10091

Vallier, L., Touboul, T., Brown, S., Cho, C., Bilican, B., Alexander, M., et al. (2009). Signaling pathways controlling pluripotency and early cell fate decisions of human induced pluripotent stem cells. Stem Cells 27, 2655-2666. doi: 10.1002/stem.199

Van Damme, P., Bogaert, E., Dewil, M., Hersmus, N., Kiraly, D., Scheveneels, W., et al. (2007). Astrocytes regulate GluR2 expression in motor neurons and their vulnerability to excitotoxicity. Proc. Natl. Acad. Sci. U.S.A. 104, 14825-14830. doi: $10.1073 /$ pnas.0705046104

Van Damme, P., Robberecht, W., and Van Den Bosch, L. (2017). Modelling amyotrophic lateral sclerosis: progress and possibilities. Dis. Model. Mech. 10, 537-549. doi: 10.1242/dmm.029058

Van Damme, P., Van Hoecke, A., Lambrechts, D., Vanacker, P., Bogaert, E., van Swieten, J., et al. (2008). Progranulin functions as a neurotrophic factor to regulate neurite outgrowth and enhance neuronal survival. J. Cell Biol. 181, 37-41. doi: 10.1083/jcb.200712039

Van Den Bosch, L., Van Damme, P., Bogaert, E., and Robberecht, W. (2006). The role of excitotoxicity in the pathogenesis of amyotrophic lateral sclerosis. Biochim. Biophys. Acta Mol. Basis Dis. 1762, 1068-1082. doi: 10.1016/j.bbadis.2006.05.002

Vucic, S., Lin, C. S., Cheah, B. C., Murray, J., Menon, P., Krishnan, A. V., et al. (2013). Riluzole exerts central and peripheral modulating effects in amyotrophic lateral sclerosis. Brain 136, 1361-1370. doi: 10.1093/brain/awt085

Wainger, B. J., Kiskinis, E., Mellin, C., Wiskow, O., Han, S. S., Sandoe, J., et al. (2014). Intrinsic membrane hyperexcitability of amyotrophic lateral sclerosis patient-derived motor neurons. Cell Rep. 7, 1-11. doi: 10.1016/j.celrep.2014.03.019

Waite, A. J., Bäumer, D., East, S., Neal, J., Morris, H. R., Ansorge, O., et al. (2014). Reduced C9ORF72 protein levels in frontal cortex of amyotrophic lateral sclerosis and frontotemporal degeneration brain with the C9ORF72 hexanucleotide repeat expansion. Neurobiol. Aging 35, 1779.e5-1779.e13. doi: 10.1016/j.neurobiolaging.2014.01.016

Wang, W., Li, L., Lin, W. L., Dickson, D. W., Petrucelli, L., Zhang, T., et al. (2013). The ALS disease-associated mutant TDP-43 impairs mitochondrial dynamics and function in motor neurons. Hum. Mol. Genet. 22, 4706-4719. doi: 10.1093/hmg/ddt319

Wang, L., Yi, F., Fu, L., Yang, J., Wang, S., Wang, Z., et al. (2017). CRISPR/Cas9mediated targeted gene correction in amyotrophic lateral sclerosis patient iPSCs. Protein Cell 8, 365-378. doi: 10.1007/s13238-017-0397-3

Webster, C. P., Smith, E. F., Bauer, C. S., Moller, A., Hautbergue, G. M., Ferraiuolo, L., et al. (2016). The C9orf72 protein interacts with Rab1 a and the
ULK1 complex to regulate initiation of autophagy. EMBO J. 35, 1656-1676. doi: 10.15252/embj.201694401

Westergard, T., Jensen, B. K., Wen, X., Cai, J., Kropf, E., Iacovitti, L., et al. (2016). Cell-to-cell transmission of dipeptide repeat proteins linked to C9ORF72ALS/FTD. Cell Rep. 17, 645-652. doi: 10.1016/j.celrep.2016.09.032

Williams, K. L., Fifita, J. A., Vucic, S., Durnall, J. C., Kiernan, M. C., Blair, I. P., et al. (2013). Pathophysiological insights into ALS with C9ORF72 expansions. J. Neurol. Neurosurg. Psychiatr. 84, 931-935. doi: 10.1136/jnnp-2012-304529

Wong, P. C., Pardo, C. A., Borchelt, D. R., Lee, M. K., Copeland, N. G., Jenkins, N. A., et al. (1995). An adverse property of a familial ALS-linked SOD1 mutation causes motor neuron disease characterized by vacuolar degeneration of mitochondria. Neuron 14, 1105-1116. doi: 10.1016/0896-6273(95) 90259-7

Xia, C., and Dickerson, B. C. (2017). Multimodal PET imaging of amyloid and tau pathology in Alzheimer disease and non-Alzheimer disease dementias. PET Clin. 12, 351-359. doi: 10.1016/j.cpet.2017.02.005

Xie, F., Ye, L., Chang, J. C., Beyer, A. I., Wang, J., Muench, M. O., et al. (2014). Seamless gene correction of $\beta$-thalassemia mutations in patientspecific iPSCs using CRISPR/Cas9 and piggyBac. Genome Res. 24, 1526-1533. doi: $10.1101 /$ gr.173427.114

Xu, Y.-F., Gendron, T. F., Zhang, Y.-J., Lin, W. L., D’Alton, S., Sheng, H., et al. (2010). Wild-type human TDP-43 expression causes TDP-43 phosphorylation, mitochondrial aggregation, motor deficits, and early mortality in transgenic mice. J. Neurosci. 30, 10851-10859. doi: 10.1523/JNEUROSCI.163010.2010

Yang, M., Liang, C., Swaminathan, K., Herrlinger, S., Lai, F., Shiekhattar, R., et al. (2016). A C9ORF72/SMCR8-containing complex regulates ULK1 and plays a dual role in autophagy. Sci Adv. 2:e1601167. doi: 10.1126/sciadv.1601167

Yu, J., Hu, K., Smuga-Otto, K., Tian, S., Stewart, R., Slukvin, I. I., et al. (2009). Human induced pluripotent stem cells free of vector and transgene sequences. Science 324, 797-801. doi: 10.1126/science.1172482

Yuan, S. H., Martin, J., Elia, J., Flippin, J., Paramban, R. I., Hefferan, M. P., et al. (2011). Cell-surface marker signatures for the isolation of neural stem cells, glia and neurons derived from human pluripotent stem cells. PLoS ONE 6:e17540. doi: 10.1371/journal.pone.0017540

Zhang, K., Donnelly, C. J., Haeusler, A. R., Grima, J. C., Machamer, J. B., Steinwald, P., et al. (2015). The C9ORF72 repeat expansion disrupts nucleocytoplasmic transport. Nature 525, 56-61. doi: 10.1038/nature14973

Zhang, W., Zhang, L., Liang, B., Schroeder, D., Zhang, Z. W., Cox, G. A., et al. (2016). Hyperactive somatostatin interneurons contribute to excitotoxicity in neurodegenerative disorders. Nat. Neurosci. 19, 557-559. doi: 10.1038/nn.4257

Zhang, Z., Almeida, S., Lu, Y., Nishimura, A. L., Peng, L., Sun, D., et al. (2013). Downregulation of MicroRNA-9 in iPSC-derived neurons of FTD/ALS patients with TDP-43 mutations. PLoS ONE 8:e76055. doi: 10.1371/journal.pone.0076055

Zhang, Z.-N., Freitas, B. C., Qian, H., Lux, J., Acab, A., Trujillo, C. A., et al. (2016). Layered hydrogels accelerate iPSC-derived neuronal maturation and reveal migration defects caused by MeCP2 dysfunction. Proc. Natl. Acad. Sci. U.S.A. 113, 3185-3190. doi: 10.1073/pnas.1521255113

Zhou, Y., and Zeng, F. (2013). Integration-free methods for generating induced pluripotent stem cells. Genomics Proteomics Bioinformatics 11, 284-287. doi: 10.1016/j.gpb.2013.09.008

Zu, T., Liu, Y., Bañez-Coronel, M., Reid, T., Pletnikova, O., Lewis, J., et al. (2013). RAN proteins and RNA foci from antisense transcripts in C9ORF72 ALS and frontotemporal dementia. Proc. Natl. Acad. Sci. U.S.A. 110, E4968-E4977. doi: $10.1073 /$ pnas. 1315438110

Conflict of Interest Statement: The authors declare that the research was conducted in the absence of any commercial or financial relationships that could be construed as a potential conflict of interest.

Copyright (C) 2017 Guo, Fumagalli, Prior and Van Den Bosch. This is an open-access article distributed under the terms of the Creative Commons Attribution License (CC $B Y)$. The use, distribution or reproduction in other forums is permitted, provided the original author(s) or licensor are credited and that the original publication in this journal is cited, in accordance with accepted academic practice. No use, distribution or reproduction is permitted which does not comply with these terms. 